\title{
Evaluation of the Global Climate Models in the CMIP5 over the Tibetan Plateau
}

\author{
FENGGE SU
}

Key Laboratory of Tibetan Environment Changes and Land Surface Processes, Institute of Tibetan Plateau Research, Chinese Academy of Sciences, Beijing, China

\section{XIAOLAN DUAN}

Key Laboratory of Tibetan Environment Changes and Land Surface Processes, Institute of Tibetan Plateau Research, Chinese Academy of Sciences, Beijing, and Fuzhou Planning Design \& Research Institute, Fuzhou, China

\section{DELIANG CHEN}

Department of Earth Sciences, University of Gothenburg, Gothenburg, Sweden

\section{ZHENCHUN HAO}

State Key Laboratory of Hydrology-Water Resources and Hydraulic Engineering, Hohai University, Nanjing, China

\section{LAN CUO}

Key Laboratory of Tibetan Environment Changes and Land Surface Processes, Institute of Tibetan Plateau Research, Chinese Academy of Sciences, Beijing, China

(Manuscript received 6 June 2012, in final form 18 October 2012)

\begin{abstract}
The performance of 24 GCMs available in the fifth phase of the Coupled Model Intercomparison Project (CMIP5) is evaluated over the eastern Tibetan Plateau (TP) by comparing the model outputs with ground observations for the period 1961-2005. The twenty-first century trends of precipitation and temperature based on the GCMs' projections over the TP are also analyzed. The results suggest that for temperature most GCMs reasonably capture the climatological patterns and spatial variations of the observed climate. However, the majority of the models have cold biases, with a mean underestimation of $1.1^{\circ}-2.5^{\circ} \mathrm{C}$ for the months December-May, and less than $1^{\circ} \mathrm{C}$ for June-October. For precipitation, the simulations of all models overestimate the observations in climatological annual means by $62.0 \%-183.0 \%$, and only half of the $24 \mathrm{GCMs}$ are able to reproduce the observed seasonal pattern, which demonstrates a critical need to improve precipitationrelated processes in these models. All models produce a warming trend in the twenty-first century under the Representative Concentration Pathway 8.5 (rcp8.5) scenario; in contrast, the rcp2.6 scenario predicts a lower average warming rate for the near term, and a small cooling trend in the long-term period with the decreasing radiative forcing. In the near term, the projected precipitation change is about $3.2 \%$ higher than the 1961-2005 annual mean, whereas in the long term the precipitation is projected to increase $6.0 \%$ under rcp 2.6 and $12.0 \%$ under the rcp 8.5 scenario. Relative to the 1961-2005 mean, the annual temperature is projected to increase by $1.2^{\circ}-1.3^{\circ} \mathrm{C}$ in the short term; the warmings under the rcp 2.6 and $\operatorname{rcp} 8.5$ scenarios are $1.8^{\circ}$ and $4.1^{\circ} \mathrm{C}$, respectively, for the long term.
\end{abstract}

Corresponding author address: Fengge Su, Key Laboratory of Tibetan Environment Changes and Land Surface Processes, Institute of Tibetan Plateau Research, Chinese Academy of Sciences, Beijing 100106, China.

E-mail: fgsu@itpcas.ac.cn

\section{Introduction}

Global climate models (GCMs) are widely used for projections of future climate change. The periodic assessments of climate change by the Intergovernmental 
Panel on Climate Change (IPCC) have relied heavily on GCM simulations of future climate driven by various emission scenarios. For the IPCC Fourth Assessment Report (AR4), 24 GCMs were used (Solomon et al. 2007; Randall et al. 2007). These archives offer unprecedented opportunities to analyze the projections for the twenty-first-century climate change and the potential effects at regional and continental scales.

At a September 2008 meeting involving 20 climate modeling groups from around the world, a working group of the World Climate Research Programme (WCRP) agreed to promote a new set of coordinated climate model experiments, and these experiments comprise the fifth phase of the Coupled Model Intercomparison Project (CMIP5). CMIP5 will notably provide a set of standardized simulations in order to 1) evaluate how realistic the models are in simulating the recent past, 2) provide projections of future climate change on two time scales, near term (out to about 2035) and long term (out to 2100 and beyond), and 3) understand some of the factors responsible for differences in model projections, including quantifying some key feedbacks such as those involving clouds and the carbon cycle.

Because of the nature of future climate simulations, testing models' ability to reproduce "present climate" and past climate changes is an important part og evaluating the GCM projections (Mote and Salathé 2010; Phillips and Gleckler 2006; Randall et al. 2007; Walsh et al. 2008). Randall et al. (2007) and Bader et al. (2008) evaluated the performance of the models archived at the Program for Climate Model Diagnosis and Intercomparison (PCMDI) in simulating various aspects of global climate in the twentieth century. Their results suggest that the models can capture the large-scale features of climate, but more uncertainties appear at regional and smaller scales and large errors occur in regions of sharp elevation changes. Phillips and Gleckler (2006) evaluated precipitation from 19 IPCC GCMs' twentieth-century runs relative to three observational estimates at both global and regional scales. Many models were found to display systematic biases, deviating markedly from the observed spatial variability and amplitude/phase of seasonal cycles. However, the ensemble mean of all the models usually shows better agreement with the observations than does any single model. Duan and Phillips (2010) presented a Bayesian multimodel method showing that multimodel prediction results are superior to individual model results and multimodel results provide an associated uncertainty estimation of the predictions. Mote and Salathé (2010) examined the simulations of twentieth-century climate in the Pacific Northwest by 20 IPCC AR4 models in relation to a gauge-based global dataset and reanalysis data. Their results show that no model fell in the best five for both temperature and precipitation, and likewise no model fell in the worst five for both. While Walsh et al. (2008) found that some models consistently rank close to the top no matter which variables and which regions are examined in their evaluation of 15 IPCC GCMs against the 40-yr European Centre for Medium-Range Weather Forecasts (ECMWF) Re-Analysis (ERA-40) data over Alaska and Greenland.

The Tibetan Plateau (TP), also known as the "Third Pole" of the world (Qiu 2008), is the highest and most extensive highland in the world (Zhang and $\mathrm{Wu} 2000$ ). The TP has an average elevation of over $4000 \mathrm{~m}$ above sea level and a total area of more than 2.5 million $\mathrm{km}^{2}$, and it exerts a huge influence on regional and global climate through mechanical and thermal forcing mechanisms (Duan and Wu 2005; Sato and Kimura 2007; Yanai et al. 1992). The TP is also the source of major Asian river systems (e.g., the Tarim, Amu Darya, Indus, Ganges, Brahmaputra, Irrawaddy, Salween, Mekong, Yellow, and Yangtze) and is considered the water tower of Asia (Immerzeel et al. 2010). These rivers support more than a billion people downstream. The TP is characterized by complex terrains, large area of snow, mountains, glaciers, permafrost, and mountain lakes. Meteorological observation and ice core records have suggested a warming trend over the TP in recent decades (around $0.3^{\circ} \mathrm{C}$ decade ${ }^{-1}$ ) (Duan et al. 2006; Liu and Chen 2000; Thompson et al. 2000; Wang et al. 2008). Also, major climate-induced changes have occurred, such as glacier retreat (Yao et al. 2004) and permafrost degradation (Wu and Zhang 2008, 2010). Changes of meteorological variables (e.g., temperature and precipitation) and the induced changes may have profound impacts on the hydrological cycle and river discharge in the TP. Therefore, quantifying the uncertainties in GCM projections of climate change over the TP is essential for assisting policymakers and water managers in adopting strategies reflecting the state of scientific understanding of the likelihood.

In this paper, we assess the ability of 24 GCMs archived by CMIP5 in reproducing the twentieth-century precipitation $(P)$ and temperature $(T)$ climatology over the TP relative to gauge observations. The twenty-first-century trends of $P$ and $T$ based on the GCMs' projections over the TP are also analyzed. The analysis of the model results described here is directed at the following questions:

- How are the models' performances over the TP in reproducing both climatological annual mean and seasonal cycle, as well as spatial variation of past and present climate?

- How would the precipitation and temperature change in the twenty-first century over the TP? 


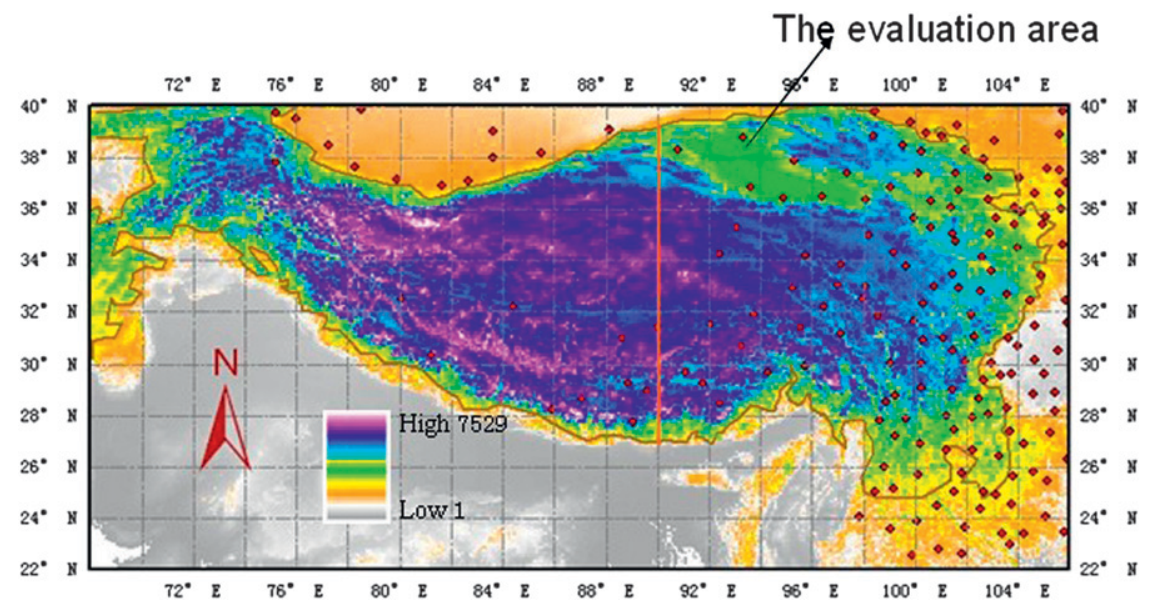

FIG. 1. Topography of the Tibetan Plateau (TP), with red dots denoting 176 meteorological stations over the TP. The region east of $90^{\circ} \mathrm{E}$ within the $2000-\mathrm{m}$ contour line (gray line) is the evaluation area in this study.

\section{Study area, data, and methodology}

The study domain in this paper is limited to the plateau extending over $22^{\circ}-40^{\circ} \mathrm{N}$ and $68^{\circ}-106^{\circ} \mathrm{E}$, with a boundary defined with the elevation above $2000 \mathrm{~m}$ (Fig. 1). Hereafter "TP" refers to the area within these boundaries. A spatial distribution of 176 meteorological stations that were used to evaluate the GCM outputs is also shown in Fig. 1. It can be seen that most of the gauges lie in the southern and southeastern TP and very few in the central and western part. The uneven distribution of the gauge stations would affect the accuracy of regional averages and the spatial interpolation. Therefore, in this study, we choose the area east of $90^{\circ} \mathrm{E}$ in the TP (hereafter eastern TP), where there is relatively dense station coverage, as our evaluation domain. Monthly temperature and precipitation data at the 176 meteorological stations (Fig. 1) for 1961-2005 were provided by the China Meteorological Data Sharing Service System (http://cdc.cma.gov.cn/) and were used to evaluate the GCM results for the same period.

Our evaluation and projection are based on the twentieth- and twenty-first-century simulations respectively by the model used in the CMIP5 (data are available online at http://pcmdi3.llnl.gov/esgcet/home.htm; note that expansions of all CMIP model acronyms are available online at http://cmip-pcmdi.llnl.gov/cmip5/docs/ CMIP5_modeling_groups.pdf). Table 1 provides basic information about the 24 GCMs. The GCM output used here consists of the monthly surface air temperature and precipitation. Most simulations were begun in the 1800s and continued through the twenty-first century, with radiative forcing and $\mathrm{CO}_{2}$ emissions prescribed from Representative Concentration Pathways (RCPs) (Meehl et al. 2007; van Vuuren et al. 2011). To facilitate GCM intercomparison and validation against the gauge observations, all the monthly fields of GCM temperature and precipitation were regridded to $2.0^{\circ}$ latitude $\times 2.0^{\circ}$ longitude grids using the nearest neighbor method, and the gauged data were interpolated to $2.0^{\circ} \times 2.0^{\circ}$ grids using the inverse distance weighting approach. For the gauged temperature, a commonly used lapse rate of $0.64^{\circ} \mathrm{C}(100 \mathrm{~m})^{-1}$ was adopted during the interpolation process from points to grids in order to take into account the elevation effects. For gauged precipitation, we simply used the inverse distance interpolation algorithm from points to $2.0^{\circ} \times 2.0^{\circ}$ grids, without considering the influence of topography on precipitation. There are 47 grid cells of $2.0^{\circ} \times 2.0^{\circ}$ within the eastern TP.

To facilitate the GCM validation against the observation data, we simply averaged the temperature and precipitation values at all the $2^{\circ} \times 2^{\circ}$ grids that fell in the eastern TP to define a regionally averaged monthly, seasonal, and annual time series of GCM simulations and observations. The annual average values of temperature and precipitation for each $2^{\circ} \times 2^{\circ}$ grid of GCMs and observations for 1961-2005 were also calculated for spatial analysis.

Several statistical measures were used to quantify the accuracy of the GCM simulations: bias $(\mathrm{AE}=\bar{S}-\bar{O}$, where $\bar{S}$ and $\bar{O}$ are simulated and observed long-term annual mean temperature or precipitation for 19612005); relative bias defined as $\mathrm{RE}=(\bar{S}-\bar{O}) / \bar{O} \times 100 \%$; correlation coefficient $R$; and root-mean-square error (RMSE). The correlation coefficient was used to describe the temporal and spatial similarity between the observation and the simulation. The mean differences between simulated and observed climate variable, 
TABLE 1. Information about the CMIP5 climate models used for IPCC AR5. Expansions of all CMIP model acronyms are available online at http://cmip-pcmdi.llnl.gov/cmip5/docs/CMIP5_modeling_groups.pdf.

\begin{tabular}{|c|c|c|c|c|}
\hline \multirow[b]{2}{*}{ Institute } & \multirow[b]{2}{*}{ Nation } & \multirow[b]{2}{*}{ Modeling Center (or group) } & \multicolumn{2}{|c|}{ Model information } \\
\hline & & & Model name & Atmosphere resolution \\
\hline $\mathrm{BCC}$ & China & $\begin{array}{l}\text { Beijing Climate Center, China } \\
\text { Meteorological Administration }\end{array}$ & BCC-CSM1.1 & $\mathrm{T} 42\left(\sim 2.8125^{\circ} \times 2.8125^{\circ}\right) \mathrm{L} 26$ \\
\hline MPI-M & Germany & Max Planck Institute for Meteorology & MPI-ESM-LR & $\mathrm{T} 63\left(\sim 1.875^{\circ} \times 1.875^{\circ}\right) \mathrm{L} 47$ \\
\hline MRI & Japan & Meteorological Research Institute & MRI-CGCM3 & $\operatorname{TL} 159\left(\sim 1.125^{\circ} \times 1.125^{\circ}\right) \operatorname{L} 48$ \\
\hline NASA GISS & USA & NASA Goddard Institute for Space Studies & $\begin{array}{l}\text { GISS-E2-H } \\
\text { GISS-E2-R }\end{array}$ & $\begin{array}{l}\sim 2^{\circ} \times 2.5^{\circ} \\
\sim 2^{\circ} \times 2.5^{\circ}\end{array}$ \\
\hline NCAR & USA & National Center for Atmospheric Research & CCSM4 & $\sim 0.9^{\circ} \times 1.25^{\circ}$ \\
\hline $\mathrm{MOHC}$ & UK & Met Office Hadley Centre & $\begin{array}{l}\text { HadCM3 } \\
\text { HadGEM2-ES } \\
\text { HadGEM2-CC }\end{array}$ & $\begin{array}{l}\mathrm{N} 48\left(\sim 2.466^{\circ} \times 3.75^{\circ}\right) \text { L19 } \\
\text { N96 }\left(\sim 1.24^{\circ} \times 1.875^{\circ}\right) \text { L38 } \\
\text { N96 }\left(\sim 1.24^{\circ} \times 1.875^{\circ}\right) \text { L60 }\end{array}$ \\
\hline $\mathrm{CCCma}$ & Canada & $\begin{array}{l}\text { Canadian Centre for Climate Modeling } \\
\text { and Analysis }\end{array}$ & $\begin{array}{l}\text { CanESM2 } \\
\text { CanCM4 }\end{array}$ & $\begin{array}{l}\mathrm{T} 63\left(\sim 2.8125^{\circ} \times 2.8125^{\circ}\right) \mathrm{L} 35 \\
\mathrm{~T} 63\left(\sim 2.8125^{\circ} \times 2.8125^{\circ}\right) \mathrm{L} 35\end{array}$ \\
\hline CSIRO & Australia & $\begin{array}{l}\text { Communication Scientific and Industrial } \\
\text { Research Organization }\end{array}$ & CSIRO-Mk3.6.0 & $\mathrm{T} 63\left(\sim 1.875^{\circ} \times 1.875^{\circ}\right) \mathrm{L} 18$ \\
\hline GFDL & USA & $\begin{array}{l}\text { NOAA Geophysical Fluid Dynamics } \\
\text { Laboratory }\end{array}$ & $\begin{array}{l}\text { GFDL-CM3 } \\
\text { GFDL-ESM2G } \\
\text { GFDL-ESM2M }\end{array}$ & $\begin{array}{l}\mathrm{C} 48\left(\sim 2^{\circ} \times 2.5^{\circ}\right) \mathrm{L} 48 \\
\operatorname{M} 45\left(\sim 2^{\circ} \times 2.5^{\circ}\right) \mathrm{L} 24 \\
\operatorname{M} 45\left(\sim 2^{\circ} \times 2.5^{\circ}\right) \mathrm{L} 24\end{array}$ \\
\hline INM & Russia & Institute for Numerical Mathematics & INM-CM4 & $\sim 1.5^{\circ} \times 2^{\circ}$ \\
\hline IPSL & France & Institute Pierre-Simon Laplace & $\begin{array}{l}\text { IPSL-CM5A-LR } \\
\text { IPSL-CM5A-MR }\end{array}$ & $\begin{array}{l}\operatorname{LMDZ}\left(\sim 41.89^{\circ} \times 3.75^{\circ}\right) \\
\operatorname{LMDZ4}\left(\sim 1.2587^{\circ} \times 2.5^{\circ}\right)\end{array}$ \\
\hline MIROC & Japan & $\begin{array}{l}\text { National Institute for Environmental } \\
\text { Studies, The University of Tokyo }\end{array}$ & $\begin{array}{l}\text { MIROC4h } \\
\text { MIROC5 } \\
\text { MIROC-ESM } \\
\text { MIROC-ESM-CHEM }\end{array}$ & $\begin{array}{l}\text { T213 }\left(\sim 0.5625^{\circ} \times 0.5625^{\circ}\right) \mathrm{L} 56 \\
\text { T85 }\left(\sim 1.40625^{\circ} \times 1.40625^{\circ}\right) \mathrm{L} 40 \\
\text { T42 }\left(\sim 2.8125^{\circ} \times 2.8125^{\circ}\right) \mathrm{L} 80 \\
\text { T42 }\left(\sim 2.8125^{\circ} \times 2.8125^{\circ}\right) \mathrm{L} 80\end{array}$ \\
\hline CSIRO-BOM & Australia & CSIRO/Bureau of Meteorology & ACCESS1.0 & $\mathrm{N} 96\left(\sim 1.25^{\circ} \times 1.875^{\circ}\right) \mathrm{L} 38$ \\
\hline $\mathrm{NCC}$ & Norway & Norwegian Climate Centre & NorESM1-M & $\mathrm{F} 19\left(\sim 1.875^{\circ} \times 2.5^{\circ}\right) \mathrm{L} 26$ \\
\hline
\end{tabular}

regardless the sign of the difference, can be described by RMSE. RMSE is defined as follows:

$$
\mathrm{RMSE}=\sqrt{\frac{\sum_{i=1}^{n}\left(O m_{i}-S m_{i}\right)^{2}}{n}},
$$

where $\mathrm{Om}_{i}$ and $\mathrm{Sm}_{i}$ denote observed and simulated temperature or precipitation, and $n$ is the number of pairs in the analysis.

For precipitation, we use the normalized RMSE (NRMSE) to describe the mean deviation of the GCMs from the observations. The NRMSE is defined as

$$
\text { NRMSE }=\frac{\text { RMSE }}{\bar{O}}
$$

where $\bar{O}$ is the mean value of the observed precipitation.

\section{Model evaluations of the twentieth-century climate}

In this section, we evaluate the performance of the 24 GCMs in reproducing the observed climatological annual mean, seasonal cycle, and spatial variation of $T$ and $P$ over the eastern TP for 1961-2005.

\section{a. Temperature}

Table 2 shows the statistical summary of the comparison between the 24 GCMs' simulations and observations of annual mean climate for 1961-2005. The observed annual mean $T$ in the eastern TP was around $2.9^{\circ} \mathrm{C}$ during $1961-2005$. Most of the 24 GCMs (20 out of 24) showed a cold bias in $T$ with negative biases ranging from $-4.35^{\circ}$ to $-0.03^{\circ} \mathrm{C}$; only four models showed a weak warm bias ranging from $0.03^{\circ}$ to $0.55^{\circ} \mathrm{C}$. The models with the least bias in annual mean $T$ are GFDLESM2M, MPI-ESM-LR, GFDL-ESM2G, CanESM2, and CanCM4 (Fig. 2). The correspondence between the modeled and observed annual temperature, in terms of interannual variation, was very poor, with the highest $R$ of 0.29 for the BCC-CSM1.1 and negative values of $R$ for 13 GCMs (Table 2). In term of the RMSE, the models with the least RMSE are MPIESM-LR, GFDL-ESM2M, GFDL-ESM2G, CanCM4, and CanESM2, ranging between $0.38^{\circ}$ and $0.51^{\circ} \mathrm{C}$, while INMCM4 performs worst with the largest RMSE of $4.39^{\circ} \mathrm{C}$. 


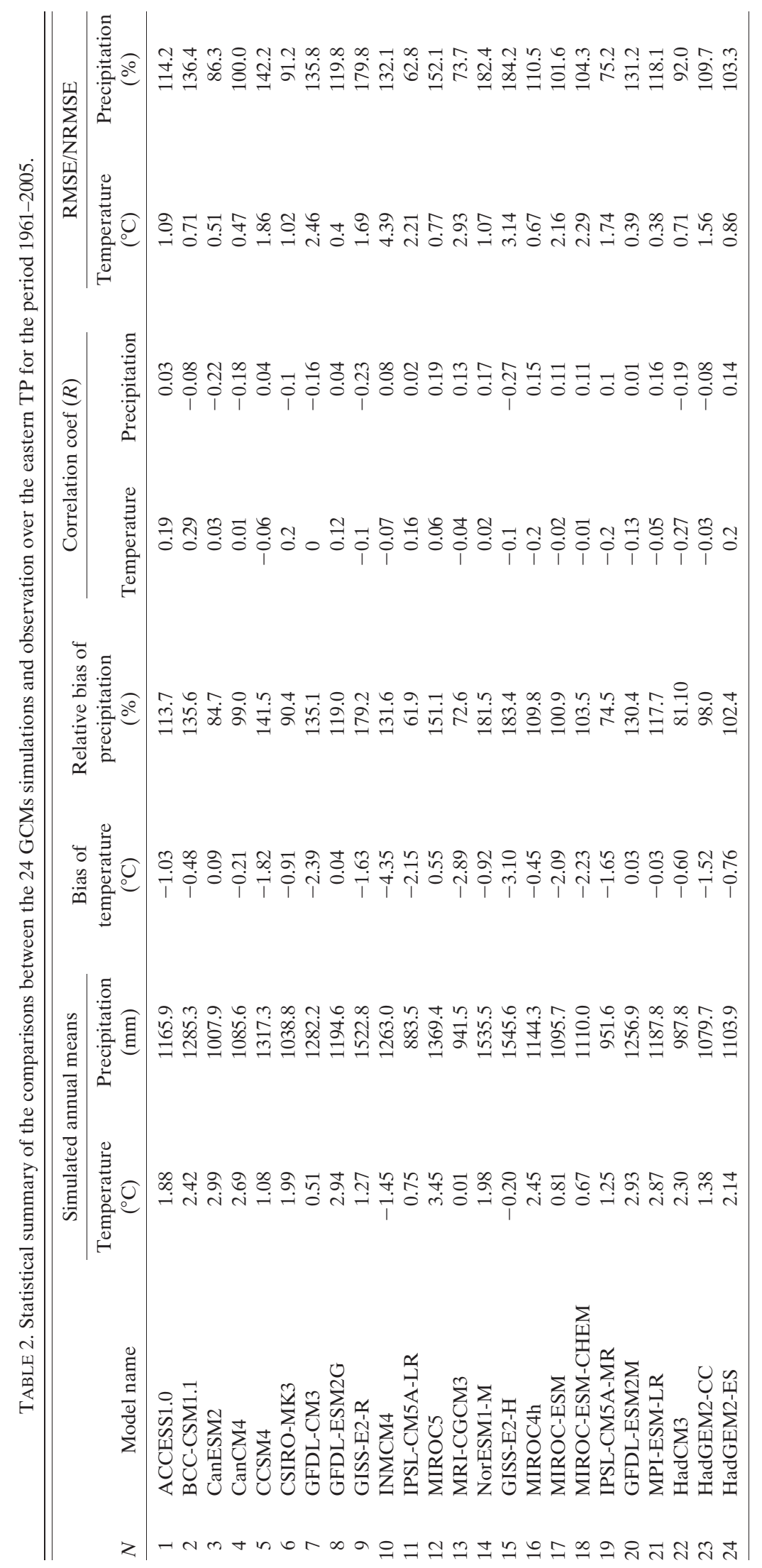




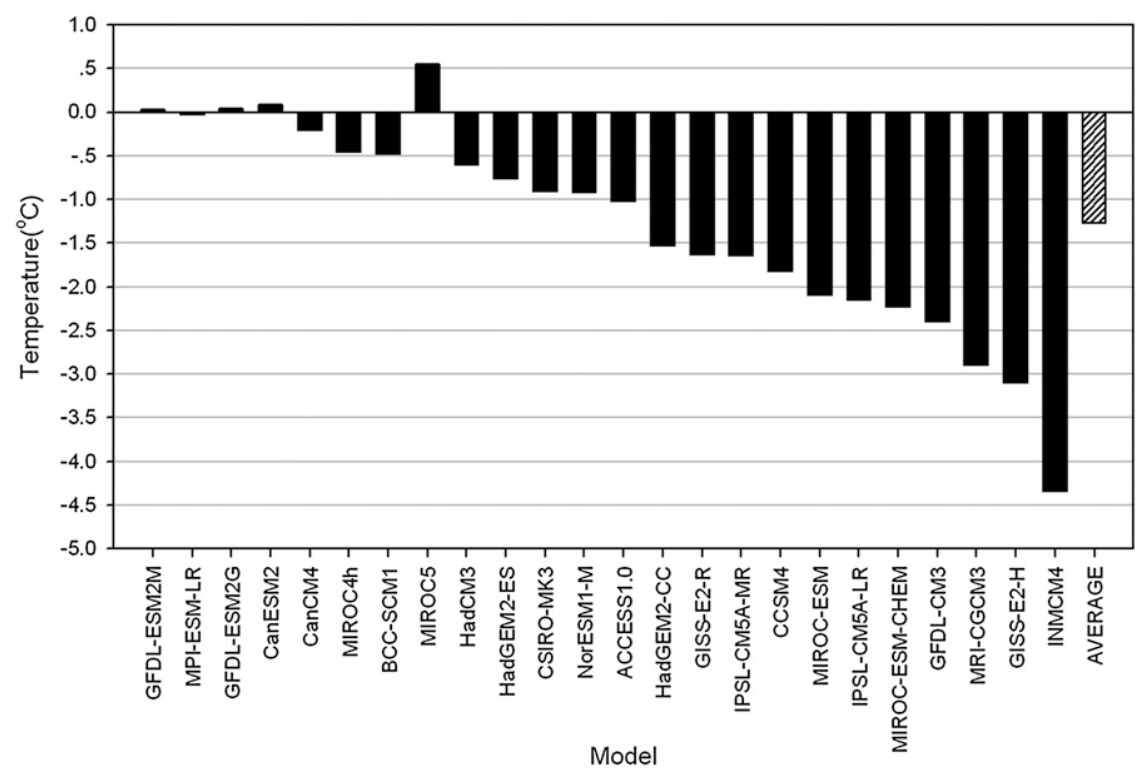

FIG. 2. Area-averaged annual bias (AE) of temperature relative to the observation for each GCM during 1961-2005 over the entire eastern TP.

Greenhouse-driven climate change represents a response to the radiative forcing associated with the increases of carbon dioxide, methane, water vapor, and other radiatively active gases, while changes in the radiative forcing associated with the greenhouse gases have thus far been relatively small, and a much more potent change in forcing occurs each year through the seasonal cycle of solar radiation (Walsh et al. 2008). In this respect, it is necessary to evaluate the models' ability to capture the seasonal cycle of past and presentday climate in the eastern TP. Figure 3 shows mean monthly temperatures from each GCM and multimodel ensemble average over the eastern TP for the period 1961-2005. The mean temperatures in summer [JuneAugust (JJA)] were around $11^{\circ}-12.5^{\circ} \mathrm{C}$ and were from $-8.2^{\circ}$ to $-5.3^{\circ} \mathrm{C}$ in winter [December-February (DJF)] based on observations. The simulations generally show similar seasonal patterns to the observation; however, most models tend to underestimate the observed $T$, especially in winter. Consistent with previous studies (e.g., Mote and Salathé 2010), the ensemble mean of the models generally shows closer agreements with the observation than individual models, with a cold bias of $1.2^{\circ}-2.5^{\circ} \mathrm{C}$ for December-April, and a cold bias less than $1^{\circ} \mathrm{C}$ for JJA. This helps to justify the multimodel approach in climate projection studies.

Figure 4 illustrates the seasonal dependencies of the RMSEs for each GCM. Although the RMSEs vary widely among models and across seasons, in most cases the RMSEs exhibit largest values in winter and smallest values in summer (Fig. 4). The models GFDL-ESM2G,
MIROC5, GFDL-ESM2M, and MPI-ESM-LR seem to perform better than the other models for all seasons in terms of RMSE (around $1.0^{\circ} \mathrm{C}$ ). The corresponding $R$ relative to the observations for each season is displayed in Table 3. Consistent with the results of RMSE, the temporal similarity between the observations and the simulation is best in summer, with 15 out of 24 models having $R$ between 0.4 and 0.7 , and worst in winter and spring with 20 models having $R$ less than 0.3 (Table 3 ). In other words, most the GCMs perform reasonably well in simulating $T$ in summer over the eastern TP; this also explains the small bias (less than $1^{\circ} \mathrm{C}$ ) in the ensemble means for JJA in Fig. 3. In summary, most of the GCMs are hardly able to simulate the interannual variations of $T$; however, most of the models can reproduce the seasonal variations of observed $T$ over the eastern TP, with the best model performance in summer.

The above analysis describes the temporal variations of $T$ from the GCMs in comparison with the observation over the eastern TP during 1961-2005; the following presents spatial variations of GCMs simulated $T$ over the TP. Figure 5 shows the spatial map $\left(2^{\circ} \times 2^{\circ}\right.$ grids $)$ of annual temperatures from the $24 \mathrm{GCMs}$, along with the observations for 1961-2005. Annual mean temperatures across the TP shift sharply from more than $23^{\circ} \mathrm{C}$ at the south of the Himalayas to less than $-18^{\circ} \mathrm{C}$ in the central to northwestern area of TP based on the observations. The lowest annual temperatures appear in the central plateau and the northwest corner where elevations are generally above $5000 \mathrm{~m}$. The temperature over the TP generally exhibits a decreasing gradient from the 


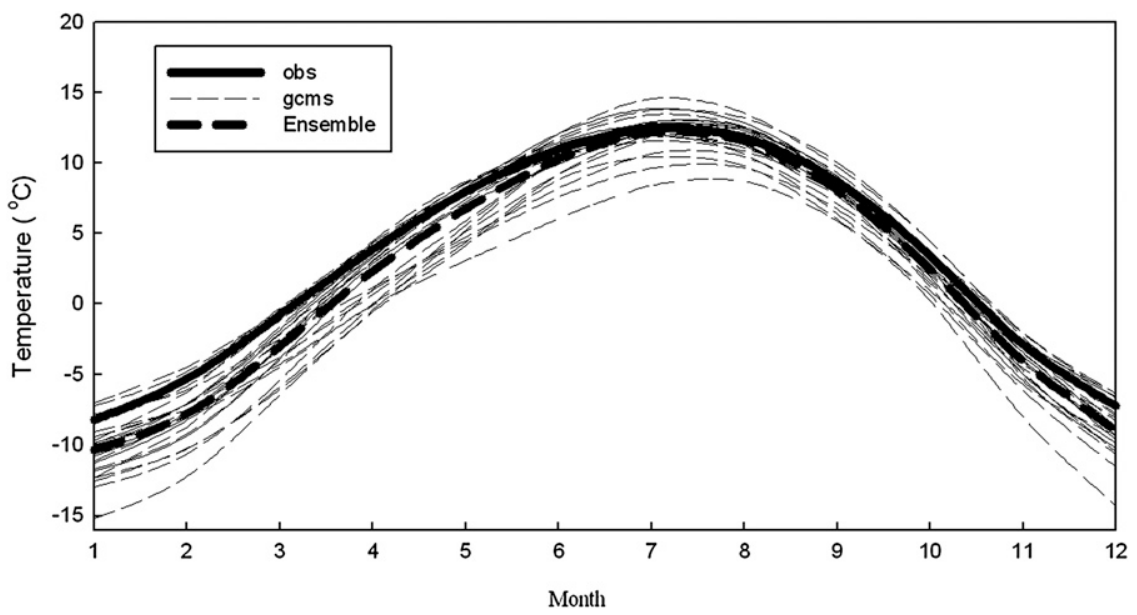

FIG. 3. Mean monthly temperatures from the 24 GCMs (gray lines) and observation (solid line) over the eastern TP for the period of 1961-2005 with the dashed line denoting the ensemble means of the 24 GCMs.

southeast to northwest with the highest temperature in the southeastern region where the elevations are low. Figure 5 indicates that most of the models show a spatial pattern similar to the observations with the spatial correlation coefficient ranging between 0.70 and 0.85 among the models relative to the observations over the eastern $\mathrm{TP}$ (based on the statistics of the forty-seven $2^{\circ} \times 2^{\circ}$ grids within the eastern TP; Table 4). The seasonal spatial patterns of temperatures for the five models with least annual biases (GFDL-ESM2M, MPI-ESM-LR, GFDL-ESM2G, CanESM2, and CanCM4) are displayed in Fig. 6. The spatial pattern of each season generally resembles that of annual means (Fig. 5). The seasonal $R$ values of temperature for all the models over the eastern TP are included in Table 4. It is interesting to note that winter temperature tends to have a better spatial correspondence with the observations than the other seasons, although winter has the highest bias (Fig. 3) and the lowest temporal $R$ (Table 3 ). The bias fields (not shown) suggest that consistent cold biases occur in the center of TP and dominant warm biases occur in the southeastern TP and the surroundings across the models in the autumn. Further, there are both positive and negative biases across the models at any location in other seasons.

\section{b. Precipitation}

In this section, we use the same approach to assess the ability of GCMs in reproducing observed climatological

\section{Temperature}

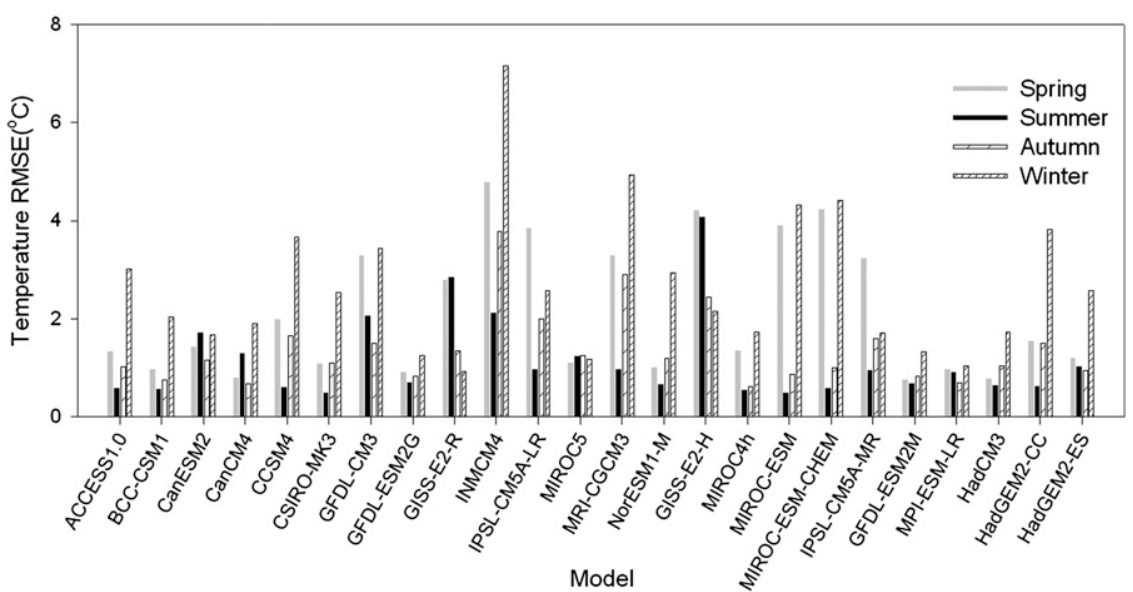

FIG. 4. The seasonal RMSEs of temperature for each GCM over the eastern TP for the period 1961-2005. 
TABLE 3. Correlation coefficient between the modeled and observed seasonal climate over the eastern TP.

\begin{tabular}{|c|c|c|c|c|c|c|c|c|}
\hline \multirow[b]{3}{*}{ Models } & \multicolumn{8}{|c|}{ Seasonal correlation coef } \\
\hline & \multicolumn{4}{|c|}{ Temperature } & \multicolumn{4}{|c|}{ Precipitation } \\
\hline & Spring & Summer & Autumn & Winter & Spring & Summer & Autumn & Winter \\
\hline ACCESS1.0 & 0.16 & 0.57 & 0.26 & 0.42 & 0.06 & 0.03 & 0.27 & -0.01 \\
\hline BCC-CSM1.1 & -0.13 & 0.48 & 0.39 & 0.08 & 0.09 & 0.37 & 0.23 & 0.11 \\
\hline CanESM2 & 0.23 & 0.42 & 0.43 & 0.18 & 0.23 & -0.08 & 0.05 & -0.29 \\
\hline CanCM4 & 0.29 & 0.59 & 0.42 & 0.23 & 0.07 & -0.03 & 0.13 & 0.28 \\
\hline CCSM4 & 0.34 & 0.56 & 0.44 & 0.39 & -0.05 & -0.08 & -0.03 & 0.22 \\
\hline CSIRO-MK3 & -0.08 & 0.42 & 0.43 & 0.14 & 0.01 & 0.09 & -0.07 & -0.11 \\
\hline GFDL-CM3 & 0.28 & 0.48 & 0.32 & 0.15 & -0.08 & -0.07 & 0.12 & -0.13 \\
\hline GFDL-ESM2G & 0.11 & 0.38 & 0.31 & 0.35 & -0.17 & -0.13 & 0.00 & -0.12 \\
\hline GISS-E2-R & 0.30 & 0.37 & 0.39 & 0.22 & 0.30 & -0.12 & 0.38 & 0.03 \\
\hline INMCM4 & -0.06 & 0.26 & 0.20 & 0.12 & 0.10 & -0.01 & -0.01 & -0.03 \\
\hline IPSL-CM5A-LR & 0.01 & 0.45 & 0.25 & 0.30 & 0.08 & 0.03 & 0.16 & -0.20 \\
\hline MIROC5 & 0.04 & 0.38 & 0.13 & 0.21 & 0.25 & -0.09 & 0.12 & -0.16 \\
\hline MRI-CGCM3 & 0.27 & 0.68 & 0.35 & 0.01 & 0.22 & 0.10 & -0.03 & 0.00 \\
\hline NorESM1-M & 0.07 & 0.70 & 0.20 & 0.40 & -0.27 & -0.12 & -0.08 & 0.14 \\
\hline GISS-E2-H & 0.30 & 0.54 & 0.42 & 0.03 & -0.13 & 0.09 & 0.48 & -0.13 \\
\hline MIROC4h & -0.02 & 0.57 & 0.31 & 0.20 & 0.01 & 0.17 & 0.02 & 0.32 \\
\hline MIROC-ESM & -0.01 & 0.52 & 0.33 & 0.15 & 0.39 & 0.04 & 0.01 & -0.05 \\
\hline MIROC-ESM-CHEM & 0.04 & 0.24 & 0.34 & -0.06 & -0.01 & 0.22 & 0.15 & 0.14 \\
\hline IPSL-CM5A-MR & 0.18 & 0.55 & 0.41 & 0.23 & -0.02 & 0.08 & -0.04 & 0.02 \\
\hline GFDL-ESM2M & -0.11 & 0.06 & 0.18 & 0.00 & 0.13 & 0.06 & 0.28 & -0.02 \\
\hline MPI-ESM-LR & 0.07 & 0.46 & 0.35 & 0.03 & -0.01 & 0.02 & 0.07 & 0.07 \\
\hline HadCM3 & 0.32 & 0.38 & 0.24 & -0.06 & 0.04 & 0.18 & -0.04 & -0.09 \\
\hline HadGEM2-CC & -0.24 & 0.17 & 0.53 & -0.20 & -0.24 & -0.22 & -0.21 & -0.11 \\
\hline HadGEM2-ES & -0.10 & 0.33 & 0.20 & 0.02 & -0.16 & -0.03 & -0.27 & -0.02 \\
\hline
\end{tabular}

annual mean, seasonal, and monthly precipitation variations. Annual mean precipitation over the eastern TP is about $545 \mathrm{~mm}$ based on the observation data for 19612005. All GCMs tend to overestimate the observed precipitation with mean REs ranging widely between $61.0 \%$ and $183.0 \%$ (Table 2). The top five models with least RE $(61.0 \%-85.0 \%)$ are IPSL-CM5A-LR, MRICGCM3, IPSL-CM5A-MR, HadCM3, and CanESM2 (Fig. 7). These five GCMs also fall into the top six models with least NRMSE (62.0\%-92.0\%; Table 2). The $R$ for annual variation of precipitation varies from -0.27 to 0.19 among the GCMs, suggesting very poor correspondences between the modeled and observed annual precipitation variations over the eastern TP.

Figure 8 shows precipitation seasonal cycles from each GCM and the multimodel ensemble mean, along with the observations over the eastern TP for the period 1961-2005. More than $80 \%$ of annual precipitation occurs during May-September and winter precipitation is very low based on the observations. The precipitation in the TP is mostly affected by monsoon in summer months and westerly wind in winter and spring. In summer months, the heavy precipitation in the southeastern TP is mainly produced by the southeast monsoon and the influence of the monsoon weakens from east to west. In winter and spring, westerly winds bring moisture to the west TP but the amount is much less than the summer precipitation from the east monsoon. Only half of the GCMs are able to reproduce the observed seasonal pattern, although these models consistently overestimate the observed precipitation for all seasons. The multimodel averages are 2.0-6.5 times higher than the observed precipitation for October-May, and are $80.0 \%$ higher than the observed for summer months. The seasonal NRMSE displayed in Fig. 9 indicates that the largest NRMSEs of precipitation occur in winter and the least in summer for most of the models, largely because the mean precipitation is higher than in winter. The seasonal precipitation from the GCMs does not correspond with the observations in terms of the seasonal $R$ for most of the models over the eastern TP (Table 3 ). One exception is the BCC-CSM1.1, which has an $R$ of 0.37 for summer and 0.27 for autumn. Despite of the low skill of most GCMs in reproducing precipitation variations for each season, the ensemble mean is able to catch the general seasonal pattern of precipitation with the wet season occurring in June-September and the dry season in November-March.

Figure 10 compares spatial pattern of annual precipitation from 24 models with those from the observation over the TP for 1961-2005. The annual means from the observation show a decreasing trend from the 

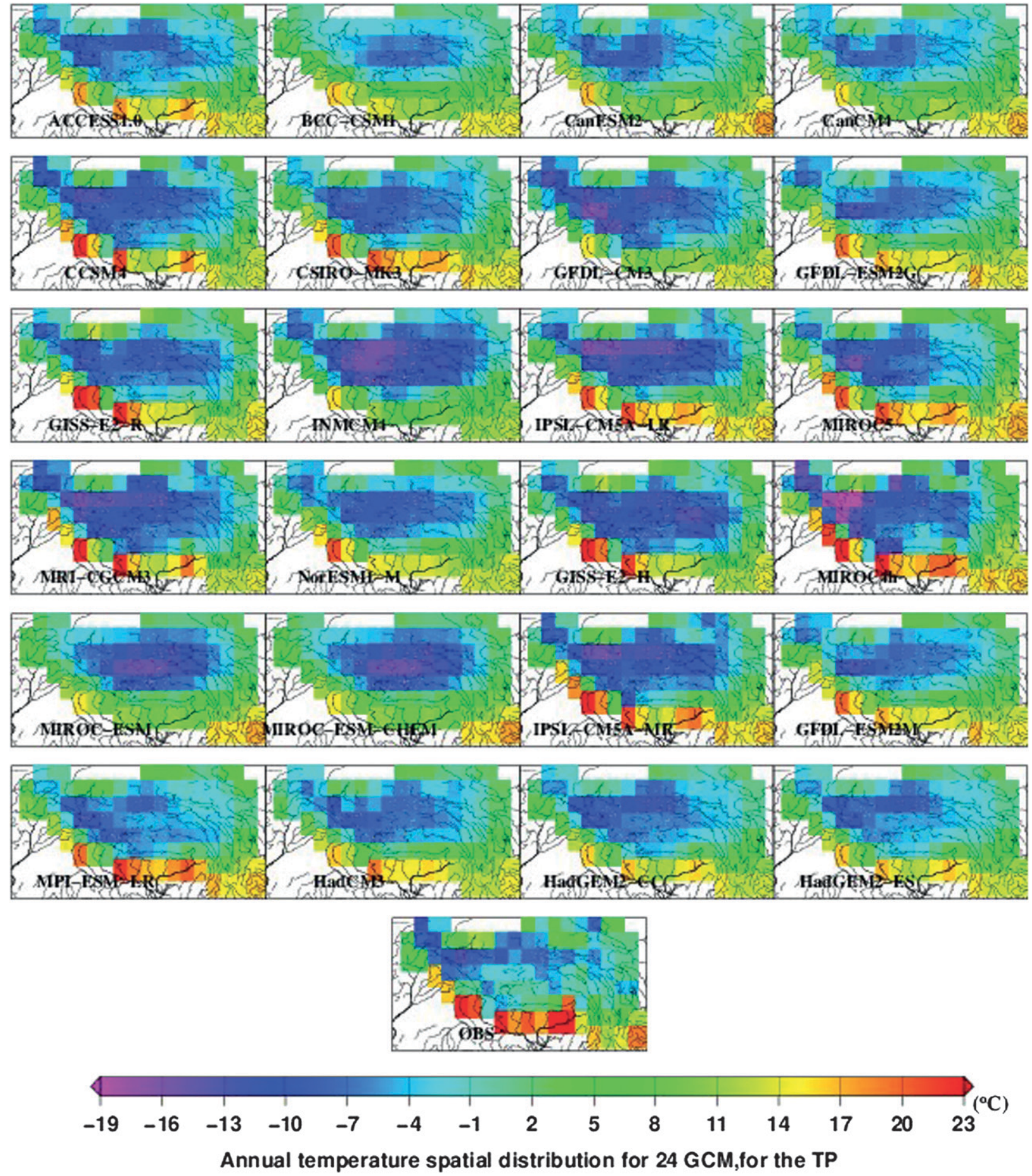

FIG. 5. Spatial pattern of annual mean temperatures from the 24 GCMs and observation over the TP at $2^{\circ} \times 2^{\circ}$ grids for $1961-2005$.

southeast to the northwest, from approximately 700 $1500 \mathrm{~mm}$ to lower than $50 \mathrm{~mm}$. The models generally followed this spatial pattern in annual means with $R$ values mostly ranging between 0.53 and 0.73 (Table 4). The spatial pattern of seasonal precipitation for the five models with least annual bias is shown in Fig. 11. The precipitation dominated by the southeast monsoon mostly occurs in summer in the southeast of the TP, and very little precipitation (less than $30 \mathrm{~mm}$ ) occurs in winter based on the observations (Fig. 11f). The five 
TABLE 4. Spatial correlation coefficient between each GCM and observations in annual and seasonal means (1961-2005) of temperature and precipitation over the eastern TP (there are total $472^{\circ} \times 2^{\circ}$ grids for the statistics).

\begin{tabular}{|c|c|c|c|c|c|c|c|c|c|c|}
\hline & \multicolumn{5}{|c|}{ Temperature } & \multicolumn{5}{|c|}{ Precipitation } \\
\hline & Annual & Spring & Summer & Autumn & Winter & Annual & Spring & Summer & Autumn & Winter \\
\hline ACCESS1.0 & 0.85 & 0.85 & 0.86 & 0.86 & 0.89 & 0.86 & 0.73 & 0.82 & 0.80 & 0.59 \\
\hline BCC-CSM1.1 & 0.78 & 0.77 & 0.80 & 0.80 & 0.84 & 0.71 & 0.63 & 0.85 & 0.85 & 0.46 \\
\hline CanESM2 & 0.78 & 0.78 & 0.79 & 0.79 & 0.86 & 0.69 & 0.78 & 0.79 & 0.75 & 0.74 \\
\hline CanCM4 & 0.79 & 0.78 & 0.79 & 0.80 & 0.86 & 0.69 & 0.77 & 0.79 & 0.75 & 0.70 \\
\hline CCSM4 & 0.85 & 0.88 & 0.87 & 0.88 & 0.89 & 0.57 & 0.70 & 0.64 & 0.57 & 0.58 \\
\hline CSIRO-MK3 & 0.82 & 0.84 & 0.84 & 0.84 & 0.88 & 0.73 & 0.82 & 0.89 & 0.79 & 0.67 \\
\hline GFDL-CM3 & 0.77 & 0.79 & 0.80 & 0.82 & 0.85 & 0.70 & 0.74 & 0.86 & 0.74 & 0.67 \\
\hline GFDL-ESM2G & 0.80 & 0.80 & 0.81 & 0.81 & 0.87 & 0.67 & 0.72 & 0.80 & 0.55 & 0.42 \\
\hline GISS-E2-R & 0.76 & 0.80 & 0.81 & 0.76 & 0.76 & 0.54 & 0.74 & 0.53 & 0.60 & 0.83 \\
\hline INMCM4 & 0.71 & 0.72 & 0.8 & 0.77 & 0.82 & 0.73 & 0.69 & 0.88 & 0.82 & 0.67 \\
\hline IPSL-CM5A-LR & 0.82 & 0.82 & 0.84 & 0.85 & 0.88 & 0.70 & 0.62 & 0.85 & 0.75 & 0.34 \\
\hline MIROC5 & 0.80 & 0.79 & 0.81 & 0.81 & 0.86 & 0.68 & 0.77 & 0.80 & 0.83 & 0.65 \\
\hline MRI-CGCM3 & 0.84 & 0.87 & 0.88 & 0.87 & 0.89 & 0.68 & 0.80 & 0.78 & 0.83 & 0.77 \\
\hline NorESM1-M & 0.80 & 0.80 & 0.80 & 0.82 & 0.87 & 0.63 & 0.76 & 0.68 & 0.61 & 0.62 \\
\hline GISS-E2-H & 0.70 & 0.74 & 0.75 & 0.71 & 0.74 & 0.56 & 0.71 & 0.54 & 0.64 & 0.79 \\
\hline MIROC4h & 0.85 & 0.86 & 0.87 & 0.87 & 0.89 & 0.64 & 0.68 & 0.79 & 0.78 & 0.73 \\
\hline MIROC-ESM & 0.71 & 0.71 & 0.74 & 0.77 & 0.79 & 0.63 & 0.61 & 0.74 & 0.59 & 0.32 \\
\hline MIROC-ESM-CHEM & 0.70 & 0.69 & 0.74 & 0.77 & 0.79 & 0.64 & 0.60 & 0.77 & 0.62 & 0.42 \\
\hline IPSL-CM5A-MR & 0.84 & 0.84 & 0.85 & 0.87 & 0.90 & 0.56 & 0.60 & 0.68 & 0.55 & 0.26 \\
\hline GFDL-ESM2M & 0.80 & 0.80 & 0.81 & 0.81 & 0.87 & 0.66 & 0.72 & 0.78 & 0.61 & 0.44 \\
\hline MPI-ESM-LR & 0.83 & 0.82 & 0.85 & 0.84 & 0.87 & 0.61 & 0.70 & 0.68 & 0.65 & 0.36 \\
\hline HadCM3 & 0.82 & 0.77 & 0.84 & 0.77 & 0.87 & 0.73 & 0.74 & 0.90 & 0.87 & 0.61 \\
\hline HadGEM2-CC & 0.84 & 0.70 & 0.86 & 0.79 & 0.89 & 0.68 & 0.75 & 0.78 & 0.80 & 0.59 \\
\hline HadGEM2-ES & 0.85 & 0.73 & 0.86 & 0.78 & 0.90 & 0.69 & 0.75 & 0.80 & 0.81 & 0.58 \\
\hline
\end{tabular}

GCMs capture the general spatial pattern of precipitation, with the highest in summer in the southeast and lowest in winter; however, the models tend to overestimate observations for all seasons for the eastern TP (Figs. 11a-e). It is noticed that, for the entire TP, the five GCMs not only detect the summer monsoon signals in the southeast of TP, but also capture the signals of western wind system in winter and spring in the western TP. (These signals were not detected in the gauge-based estimates because of the limited stations in the west of TP.) The $R$ index for each season over the eastern TP (Table 4) shows that summer season generally has the best spatial correspondence with the observations (18 out of 24 models having $R$ values of 0.7-0.9), suggesting that most of GCMs are able to detect the monsoon signals.

\section{Projected changes in temperature and precipitation}

IPCC AR4 produces six global greenhouse gas emissions scenarios ranked from highest to lowest in terms of global average emissions at midcentury as AIFI, A2, A1B, B2, A1T, and B1. The scenario development has been carried out as a sequential process from socioeconomics and emissions to climate projections and finally impact assessment. This sequential process prolonged the integration of information across the three research communities. A new set of scenarios to facilitate future assessment of climate change, compatible with the full range of stabilization, mitigation and baseline emission scenarios available in the scientific literature, has been developed by the research community (van Vuuren et al. 2011; Moss et al. 2010). These scenarios are referred to as representative concentration pathways. The identification of RCPs upfront is done to expedite the development of integrated scenarios by enabling climate modeling to proceed in parallel to emission and socioeconomic scenario development. The RCPs have now been agreed upon that specify radiative forcing through the end of the twenty-first century (Moss et al. 2010). The philosophy of the RCP scenarios is to provide a single implementation of concentrations and radiative forcing in line with the scenario literature as evaluated for IPCC AR4. It is part of the Fifth Assessment Report (AR5) process to characterize the uncertainties in a comprehensive manner. In this paper, rcp2.6 (rcp3-pd) and rcp8.5 were selected for investigating the twenty-first century climate projections over the TP as they represent the extreme condition of radiative forcing and emissions. Rcp 8.5 is the highest forcing and emission scenario, with an increasing radiative forcing to $8.5 \mathrm{~W} \mathrm{~m}^{-2}$ at 2100 ; rcp 2.6 , by contrast, generally represents the lowest forcing and emission 


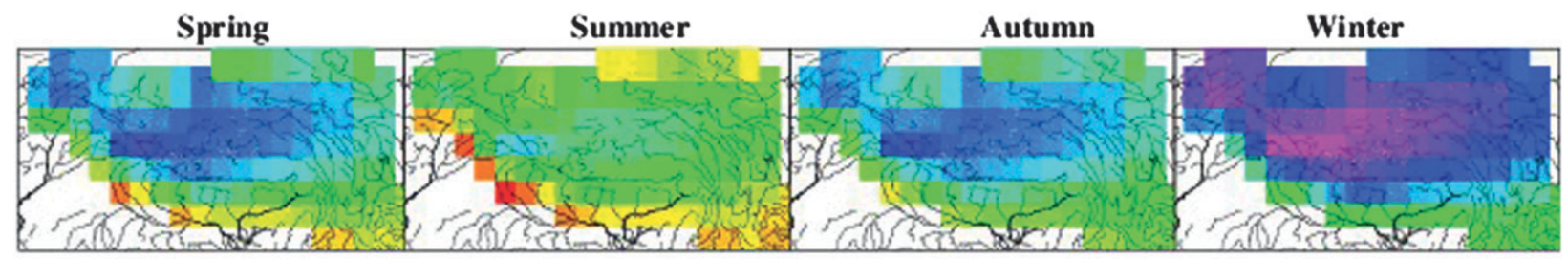

(a)GFDL-ESM2M

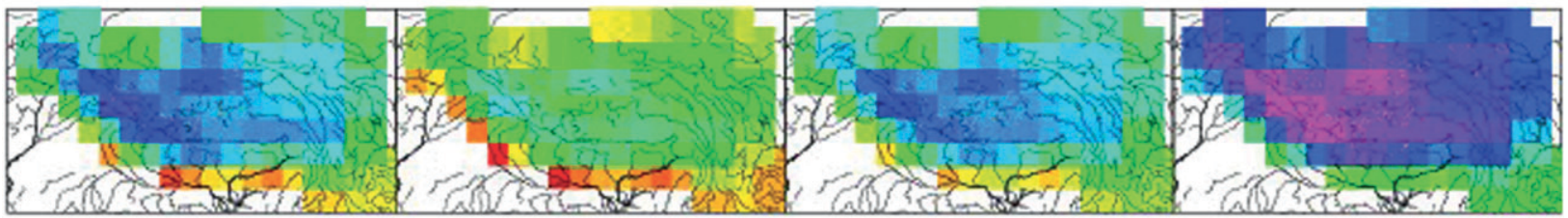

(b) MPI-ESM-LR

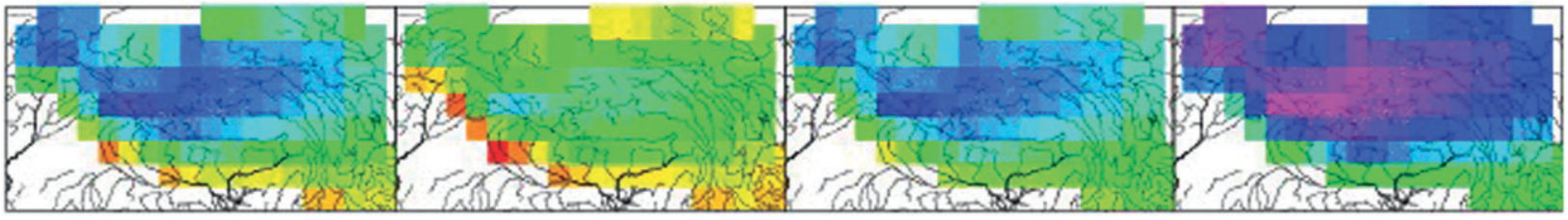

(c)GFDL-ESM2G

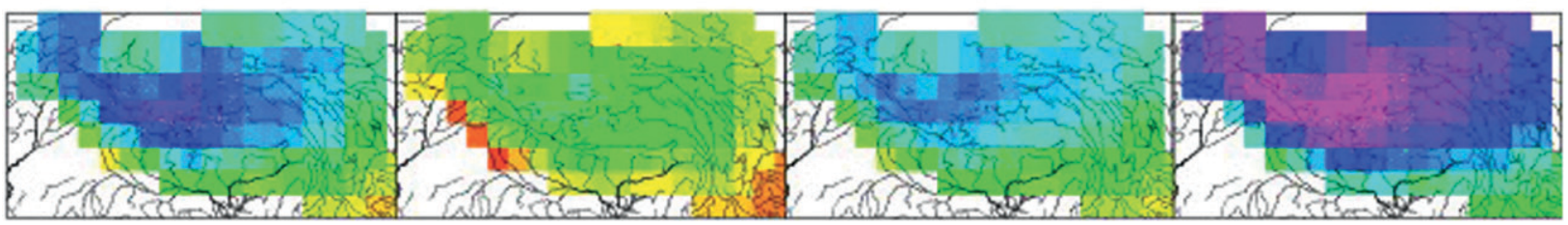

(d)CanESM2

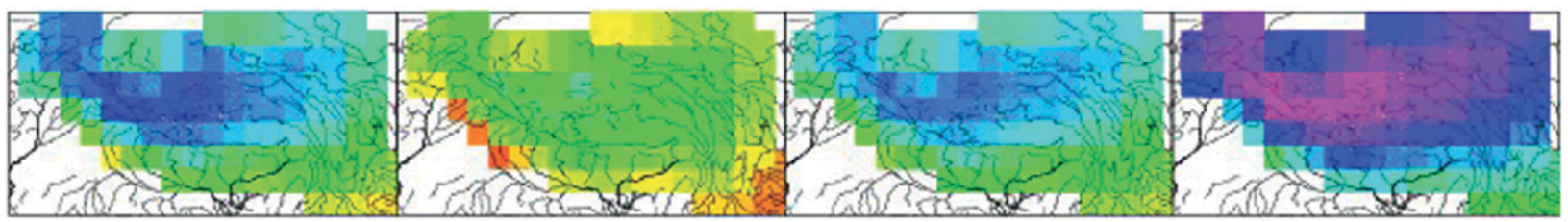

(e)CanCM4

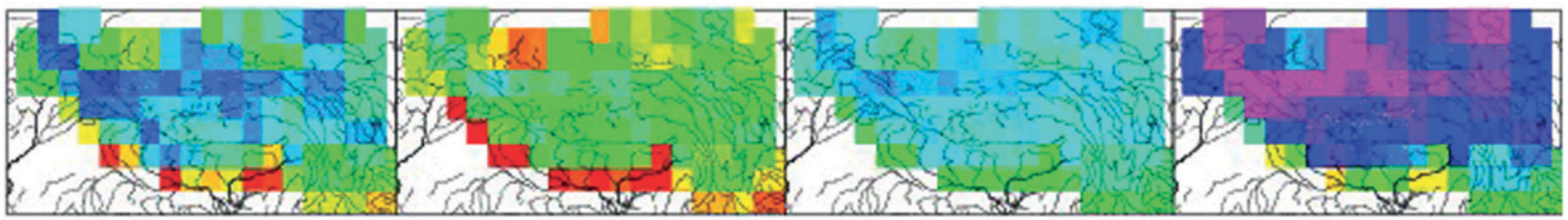

(f)OBS

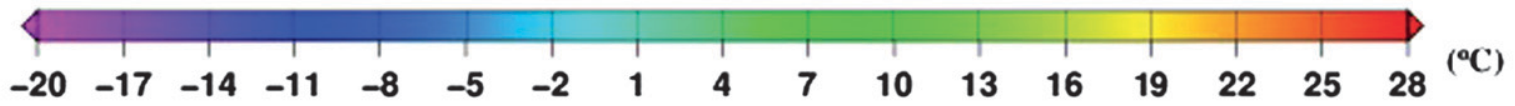

Seasonal spatial distribution of temperature shift for $5 \mathrm{GCM}$ with the least bias,for the TP

FIG. 6. Seasonal spatial patterns of temperatures from the five GCMs with least annual biases with respect to the observation for 1961-2005. 


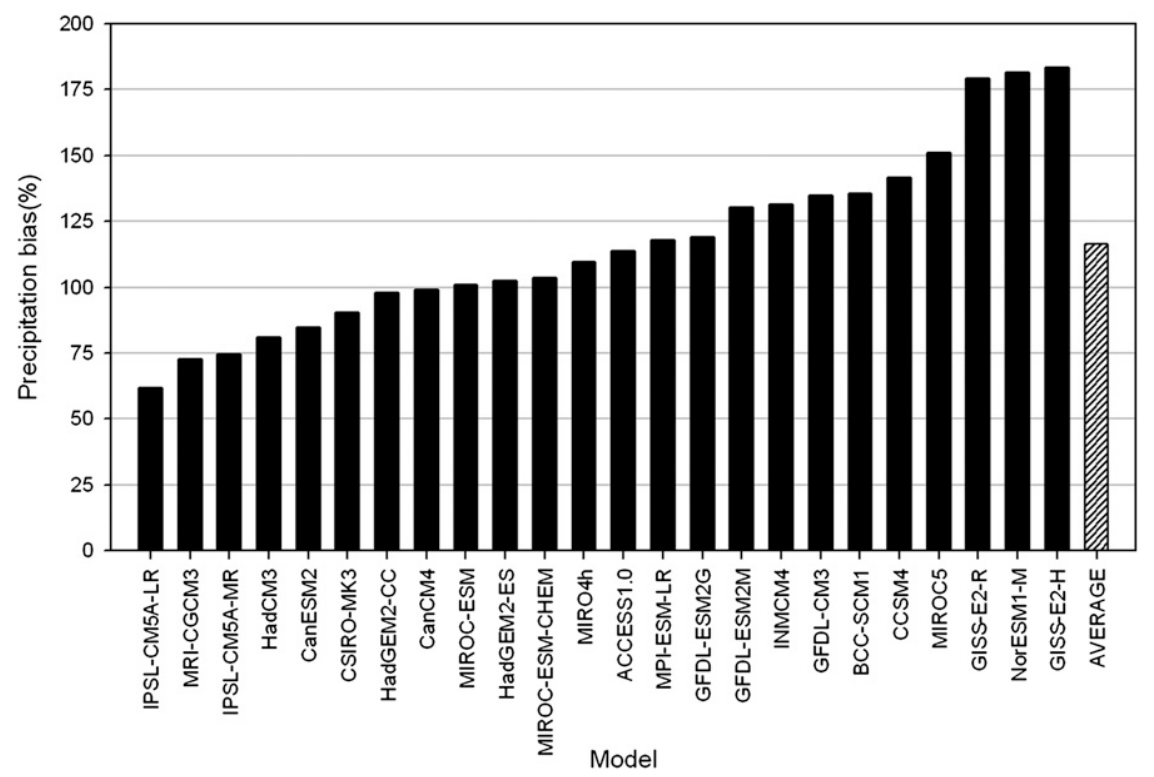

FIG. 7. Area-averaged annual relative bias (RE) of precipitation relative to the observation for each GCM during 1961-2005 over the entire eastern TP.

scenario throughout the twenty-first century, with a forcing peaking in 2035 at around $3 \mathrm{~W} \mathrm{~m}^{-2}$ and decreasing to $2.6 \mathrm{~W} \mathrm{~m}^{-2}$ by 2100 .

One of CMIP5's aims is to provide projections of future climate change on two time scales, near term (out to about 2035) and long term (out to 2100 and beyond). Therefore, in this section, we present the projected changes of climate over the TP in the twenty-first century with two time scales under scenarios of rep8.5, and rcp2.6 (rcp3-pd). Hereafter, "1980s" denotes the 1961-2005 average, "near term" denotes the 2006-35 average, and "long term" donates the 2036-99 average.
Table 5 presents the prediction of linear trends of annual mean precipitation and temperature from each GCM on the TP for the near term and long term under scenarios rcp2.6 and rcp8.5. There are 13 models involved for rep2. 6 and 16 for rep8.5 because of the unavailability of some model outputs at the time preparing this manuscript. The annual mean precipitation on the $\mathrm{TP}$ is generally projected to increase in the twenty-first century; however, there are great discrepancies in the changing rates among the models for both terms and scenarios (Table 5). Under scenario rcp2.6, the increasing trends of annual precipitation range between

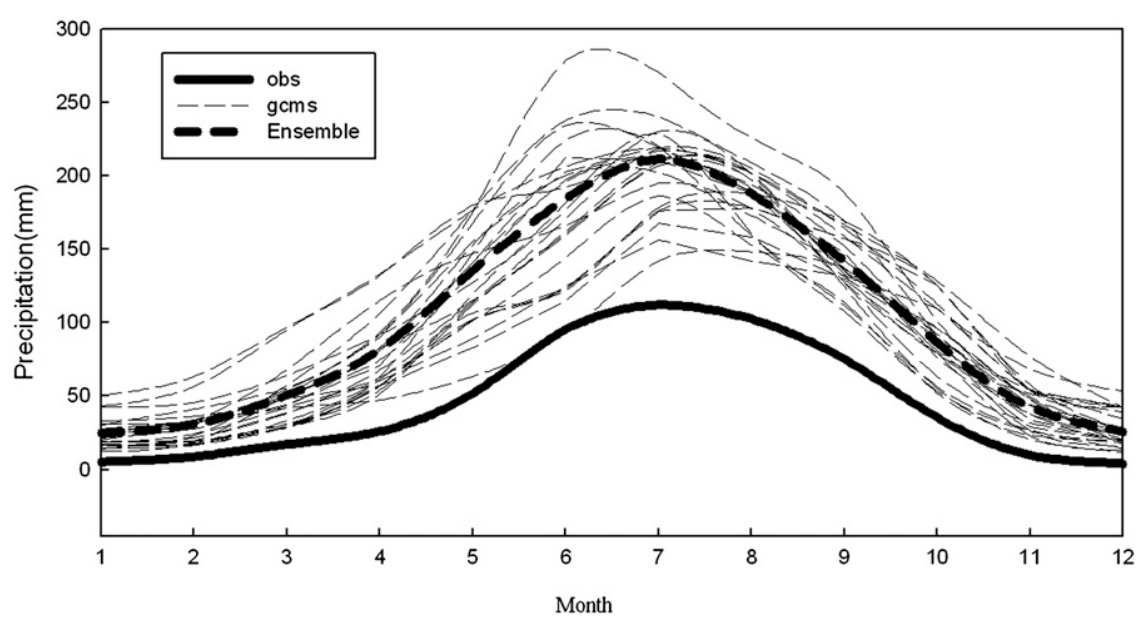

FIG. 8. Mean monthly precipitation from the $24 \mathrm{GCMs}$ and observation (solid line) over the eastern TP for the period 1961-2005, with the dashed line denoting the ensemble mean of the 24 GCMs. 


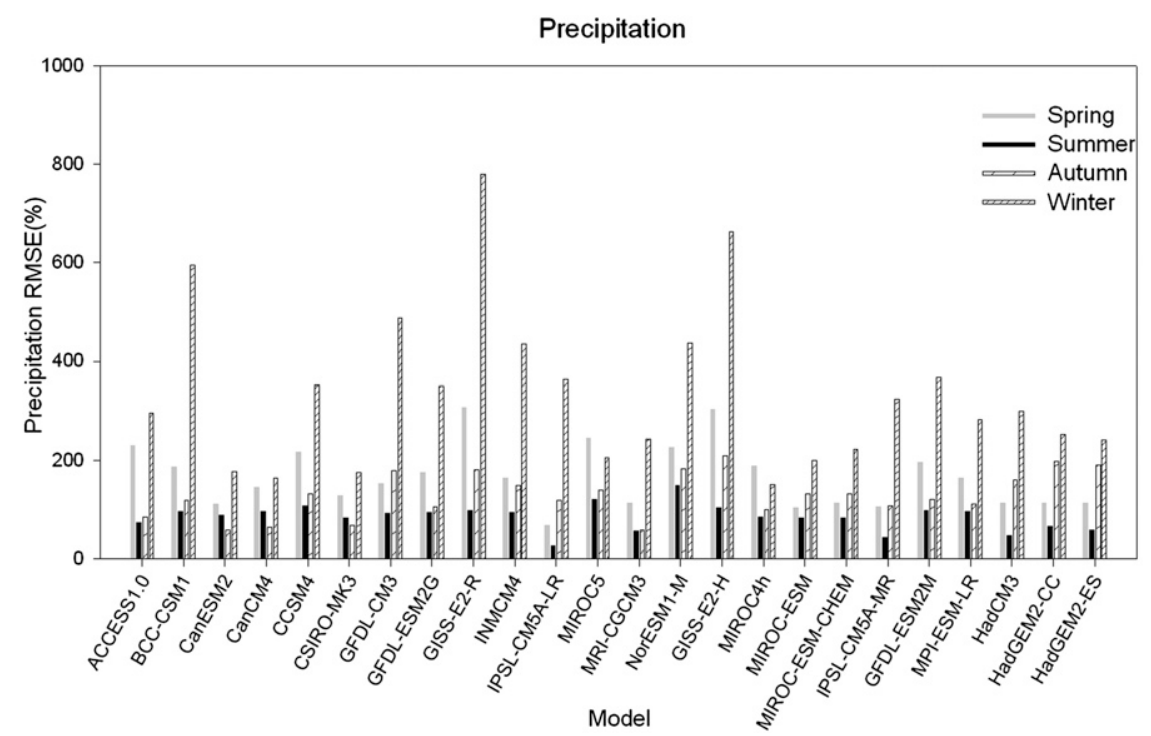

FIG. 9. The seasonal NRMSEs of precipitation for each GCM over the eastern TP for the period 1961-2005.

6.0 and $48.0 \mathrm{~mm}(10 \mathrm{yr})^{-1}$ among the models with an average trend of $13.9 \mathrm{~mm}(10 \mathrm{yr})^{-1}$ for the near term, while the mean increasing rate drops to $2.2 \mathrm{~mm}(10 \mathrm{yr})^{-1}$ for the long term (2036-99). For scenario rcp8.5, the average increase rate of annual precipitation is $9.7 \mathrm{~mm}$ $(10 \mathrm{yr})^{-1}$ for the short term and the mean increasing trend nearly doubles for the long term $\left[18.3 \mathrm{~mm}(10 \mathrm{yr})^{-1}\right]$.

For the annual temperature, all the models predict a steadily increasing trend in the twenty-first century under rcp8.5 with an average warming rate of $0.47^{\circ} \mathrm{C}(10 \mathrm{yr})^{-1}$ for the near term and $0.73^{\circ} \mathrm{C}(10 \mathrm{yr})^{-1}$ for the long term. On the contrast, rcp2.6 predicts a lower average warming rate of $0.33^{\circ} \mathrm{C}(10 \mathrm{yr})^{-1}$ for the near term and a light cooling trend of $0.01^{\circ} \mathrm{C}(10 \mathrm{yr})^{-1}$ for the long-term period (Table 5).

The evolution of regionally averaged annual temperature and precipitation for rcp2.6 and rcp 8.5 simulations are more clearly illustrated in Fig. 12, along with the average value for each year. The multimodel averages highlight the region's response to different forcing scenarios on century time scales. The ensembles of projections show apparent differences between scenarios rcp2.6 and rcp8.5. For precipitation, the increasing trend for the twenty-first century of rcp 8.5 is much more significant than that of rep2.6 and the range among models is much wider than the precipitation trends. The temperature projections show consistently increasing trends for rcp 8.5 in the twenty-first century; note that while the projected mean temperatures under rcp2.6 show the warmest time around 2035, then the temperature would decrease following the evolution of radiative forcings under rcp2.6.
Figure 13 quantifies the projected changes in response to different forcing scenarios for the near term and long term. One axis is the change of annual mean temperature and another the change of annual mean precipitation relative to the long-term mean for 1961-2005. In Fig. 13, temperature change and precipitation change seem to be correlated for some models. For example, CanESM2 and GFDL-CM3 tend to be the wettest and warmest in each period and each scenario; MPI-ESMLR and MRI-CGCM3 tend to be the coolest and driest. The increase of temperature and the difference among scenarios are small in the near term with the ensemble average temperature increase between $1.2^{\circ}$ and $1.3^{\circ} \mathrm{C}$ for two scenarios. The average precipitation change in the short term relative to the 1961-2005 mean is about 3.2\% for both rcp2.6 and rcp8.5 (Fig. 13a), suggesting the insensitivity of precipitation changes to emission scenarios in the short term. The temperature and precipitation changes and the difference between scenarios become substantial as time evolves (Fig. 13b). The mean increase of temperature and precipitation in the long term relative to the $1961-2005$ mean is $1.8^{\circ} \mathrm{C}$ and $6.0 \%$, respectively, for $\mathrm{rcp} 2.6$, and $4.1^{\circ} \mathrm{C}$ and $12.0 \%$ for rcp8.5.

For some applications the changes of climate in a given season may be more important than the changes in the annual mean. Figures 14 and 15 show seasonal changes in temperature and precipitation for the near term and long term relative to the 1980s (1961-2005). The projected temperature changes in the near term show weak seasonality over the TP for both scenarios. Winter and spring tend to have slightly larger warming 

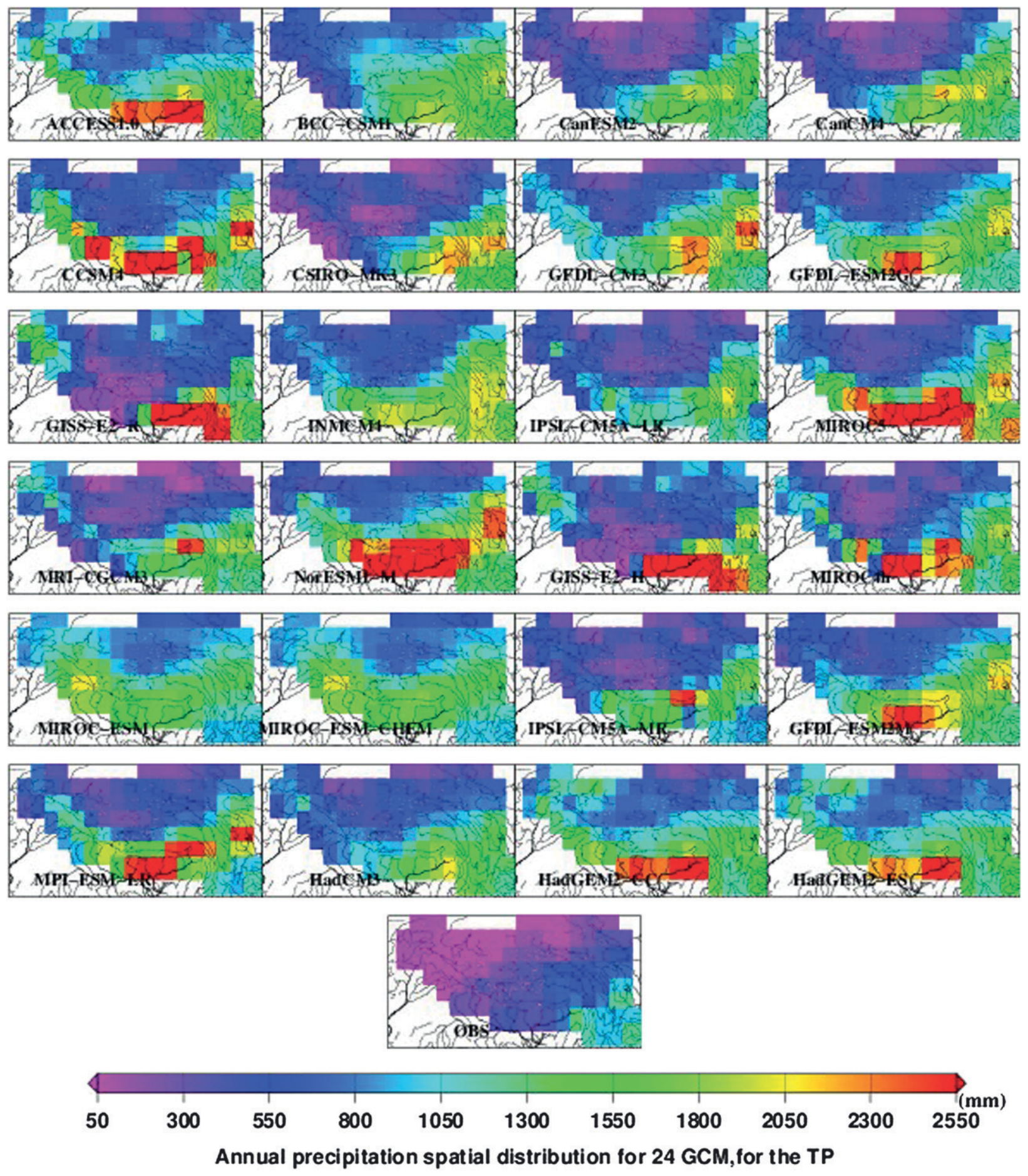

FIG. 10. Spatial pattern of annual precipitation from the 24 GCMs and the observation and over the TP for 1961-2005.

rates than those of summer and autumn, with an average temperature rises of $1.2^{\circ}-1.4^{\circ} \mathrm{C}$ in winter and spring and $1.1^{\circ}-1.3^{\circ} \mathrm{C}$ in summer and autumn for the near term. Consistent with the results in Fig. 14b, the temperature increase and the dispersion between scenarios turn out to be large in the long term, with a mean warming of $1.7^{\circ}-2.0^{\circ} \mathrm{C}$ among the four seasons for rcp2.6, and $3.9^{\circ}-$ $4.6^{\circ} \mathrm{C}$ for rep8.5 relative to the $1961-2005$ mean. Winter is projected to warm the most and summer the least for both scenarios. Winter and spring also tend to have 


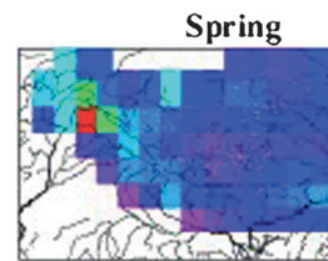

Summer

Autumn

Winter
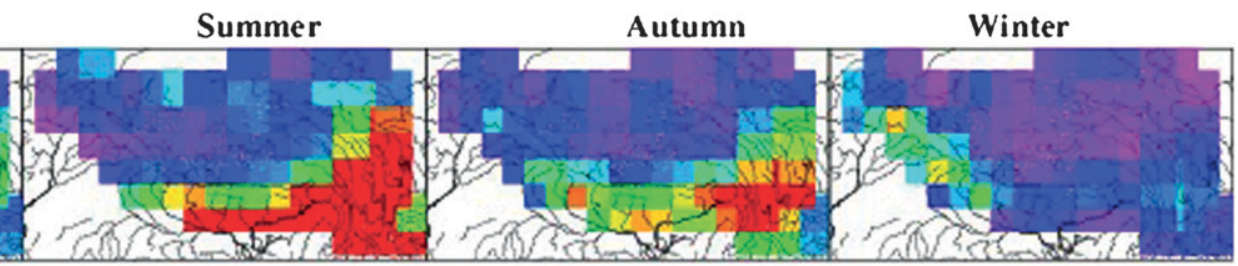

(a)IPSL-CM5A-LR

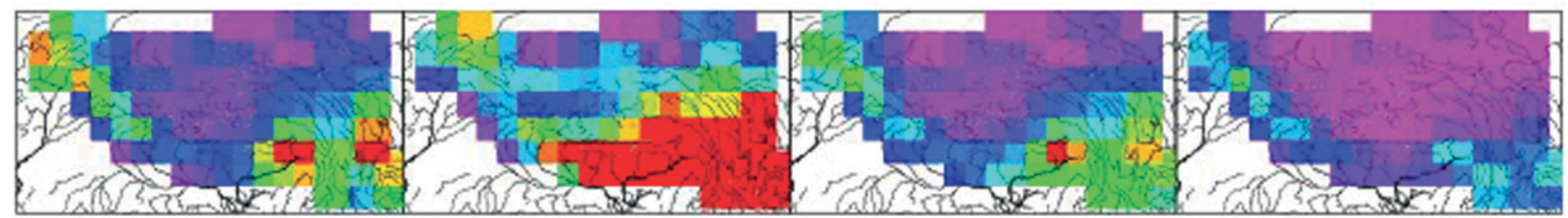

(b)MRI-CGCM3

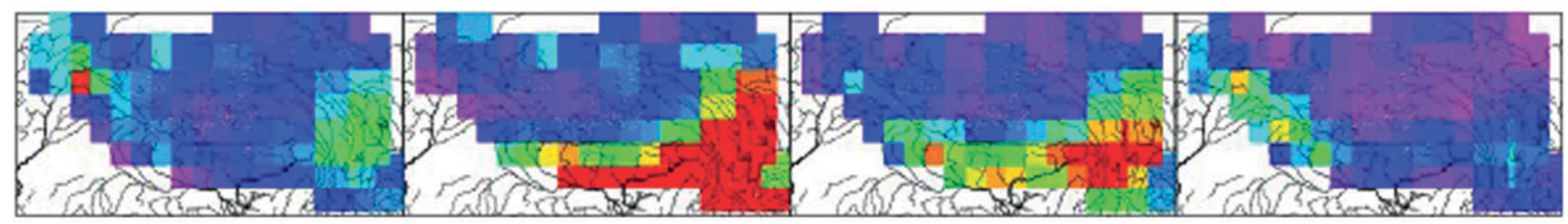

(c)IPSL-CM5A-MR

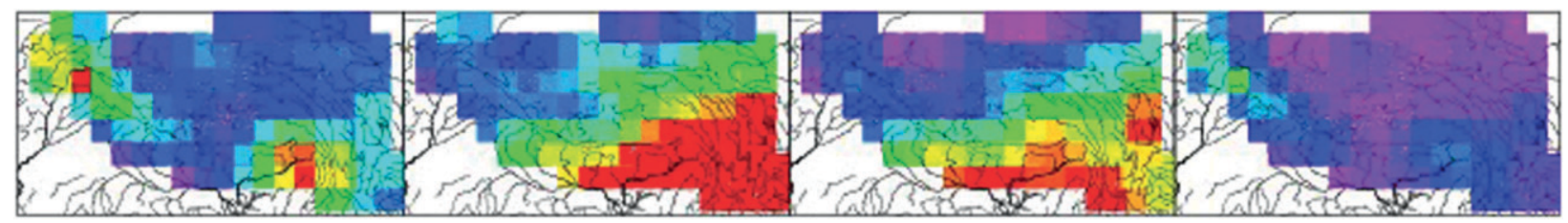

(d)HadCM3

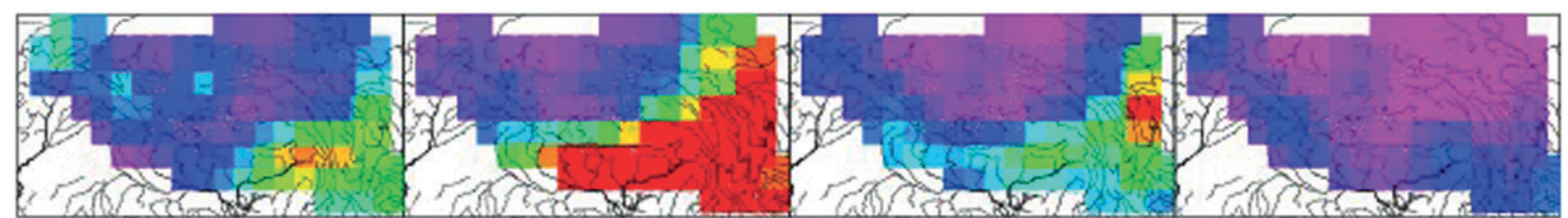

(e)CanESM2

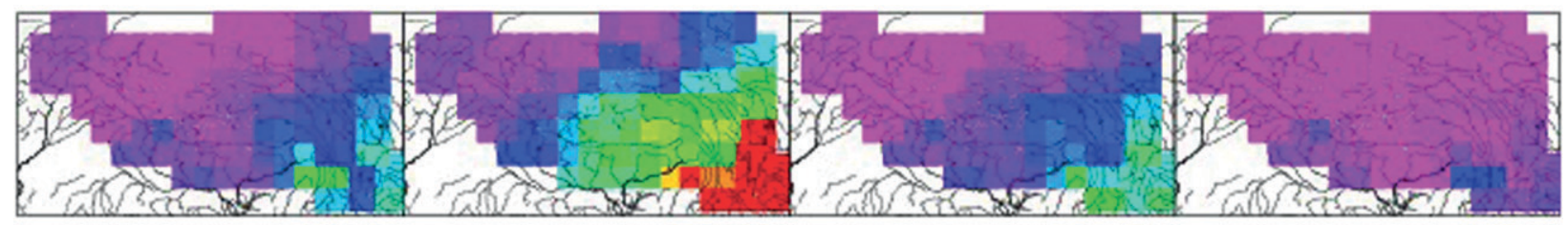

(f) OBS

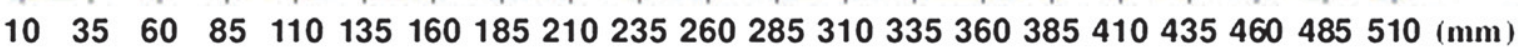

Seasonal precipitation spatial distribution for 5 GCM with the least bias, for the TP

FIG. 11. Seasonal spatial patterns of precipitation from the five models with least bias with respect to the observations over the TP for 1961-2005. 
TABLE 5. Projected trends of temperature $\left[{ }^{\circ} \mathrm{C}(10 \mathrm{yr})^{-1}\right]$ and precipitation $\left[\mathrm{mm}(10 \mathrm{yr})^{-1}\right]$ for the near term and long term under rcp2.6 and rcp8.5.

\begin{tabular}{|c|c|c|c|c|c|c|c|c|}
\hline \multirow[b]{3}{*}{ Model } & \multicolumn{4}{|c|}{ rcp2.6 } & \multicolumn{4}{|c|}{ rcp8.5 } \\
\hline & \multicolumn{2}{|c|}{ Precipitation } & \multicolumn{2}{|c|}{ Temperature } & \multicolumn{2}{|c|}{ Precipitation } & \multicolumn{2}{|c|}{ Temperature } \\
\hline & Near term & Long term & Near term & Long term & Near term & Long term & Near term & Long term \\
\hline BCC-CSM1.1 & 12.0 & 1.5 & 0.33 & -0.10 & -19.8 & 27.8 & 0.40 & 0.60 \\
\hline CanESM2 & 5.1 & 4.5 & 0.33 & -0.07 & 16.8 & 37.6 & 0.67 & 0.78 \\
\hline CCSM4 & -6.4 & 4.3 & 0.27 & -0.04 & 12.5 & 16.4 & 0.30 & 0.57 \\
\hline GFDL-CM3 & - & - & - & - & 16.9 & - & 0.67 & 0.96 \\
\hline GFDL-ESM2G & 9.6 & 3.9 & -0.03 & -0.07 & 12.1 & - & 0.20 & - \\
\hline GFDL-ESM2M & 24.8 & -2.1 & 0.23 & -0.04 & 7.6 & 15.1 & 0.33 & - \\
\hline GISS-E2-R & 16.3 & 1.1 & 0.20 & -0.10 & 5.1 & 17.0 & 0.43 & 0.44 \\
\hline INMCM4 & - & - & - & - & 17.5 & 16.4 & 0.33 & 0.62 \\
\hline IPSL-CM5A-LR & 18.6 & -1.1 & 0.37 & 0.04 & 0.6 & 2.5 & 0.57 & 0.86 \\
\hline IPSL-CM5A-MR & 2.4 & 3.8 & 0.40 & -0.03 & 8.2 & 0.4 & 0.43 & 0.92 \\
\hline MIROC5 & 48.1 & -2.8 & 0.53 & 0.02 & 29.8 & 35.8 & 0.67 & 0.67 \\
\hline MIROC-ESM & 17.1 & 10.3 & 0.57 & - & 22.4 & 19.6 & 0.73 & 0.93 \\
\hline MIROC-ESM-CHEM & 13.2 & 5.1 & 0.60 & 0.08 & 24.5 & 23.0 & 0.73 & 0.95 \\
\hline MPI-ESM-LR & - & - & - & -0.02 & 2.9 & -6.4 & 0.37 & 0.70 \\
\hline MRI-CGCM3 & 6.5 & -3.8 & 0.17 & 0.04 & 5.6 & 22.3 & 0.27 & 0.62 \\
\hline NorESM1-M & 13.6 & 4.1 & 0.27 & 0.02 & -7.4 & 28.6 & 0.40 & 0.59 \\
\hline AVERAGE & 13.9 & 2.2 & 0.33 & -0.01 & 9.7 & 18.3 & 0.47 & 0.75 \\
\hline
\end{tabular}

larger intermodel variability than the other seasons for both periods and scenarios (Fig. 14).

The precipitation changes projected by the models vary from negative to positive for each season (Fig. 15). However, on the whole, more than half of the simulations show an increase in precipitation relative to the 1961-2005 seasonal mean. Summer, autumn, and spring tend to have larger precipitation increases than winter for both the near term and long term based on the ensemble averages, with a mean increase of $5 \%-7 \%$ in summer, autumn, and spring and $2 \%-4 \%$ in winter during the near term. The difference of projected precipitation changes among scenarios is within $2 \%$ for all seasons in the near term of the twenty-first century (Fig. $15 \mathrm{a})$, suggesting the insensitivity of precipitation to different forcing scenarios in this period. In the long term, the mean projected precipitation changes and the difference between the scenarios become large, with $10.0 \%-15.0 \%$ changes in spring, summer, and autumn and $6.0 \%$ in winter for rep8.5, and with $5.0-7.0 \%$ in spring, summer, and autumn and $3.0 \%$ in winter for rcp2.6. Similar to temperature, the largest variability of precipitation among models tends to occur in winter for all the periods and scenarios (Fig. 15).

\section{Discussion}

In this study, we evaluate the ability of 24 GCMs used in the CMIP5 in describing temperature and precipitation over the eastern TP by comparing with ground observations for 1961-2005. Most GCMs can capture the general seasonal and spatial patterns of precipitation and temperature in the observation for the study domain and can detect the summer monsoon signals in the southeastern TP and western wind system in winter and spring (Figs. 10 and 11). However, the multimodel mean tends to underestimate observed temperature and overestimate precipitation over the eastern TP on average. A cold and wet bias was also identified over the Tibetan Plateau (with the median of $-2.5^{\circ} \mathrm{C}$ in annual average temperature and $110 \%$ in precipitation) in the IPCC AR4 GCMs (Christensen et al. 2007). The CMIP5 models did not show significant improvements for the simulations of precipitation and temperature over the TP, suggesting that similar model deficiencies still remain.

Cold bias seems to be a persistent feature in the GCMs. The composite surface air temperatures from 14 GCMs in the IPCC AR4 for 1981-2000 were generally $1^{\circ}-2^{\circ} \mathrm{C}$ colder than corresponding observations in the Arctic (Chapman and Walsh 2007). The cold bias reached $-7^{\circ} \mathrm{C}$ in the ensemble mean of the AR4 models in the northeast of European Russia in winter (Christensen et al. 2007). The general cold bias in the GCMs implies that most of the models suffer from a common deficiency in some aspects of their formulation, despite the marked differences in resolution and the diversity of their physical parameterizations.

A consistent wet bias was also found over the entire Asia in the IPCC AR4 models, with the largest appearing in the Tibetan Plateau (Christensen et al. 2007). It is beyond the scope of the present study to diagnose 

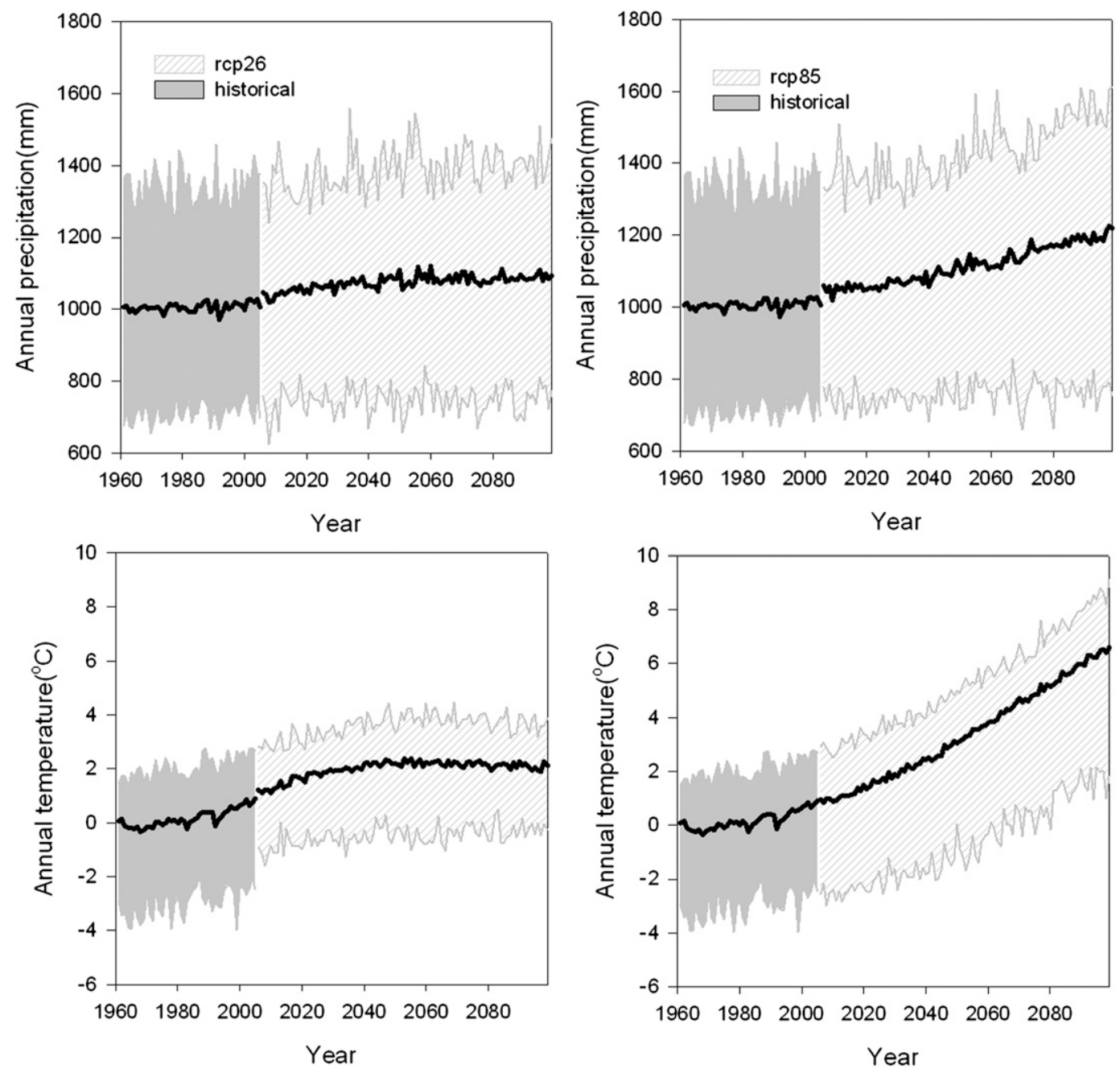

FIG. 12. Simulated traces in (bottom) temperature and (top) precipitation for a subperiod (1961-2005) of the twentieth and twenty-first century for the entire TP. The heavy black curves represent the average value, calculated for each year. The top and bottom bounds of the shaded area are the maximum and minimum of the annual value from the $24 \mathrm{GCM}$ simulations. Mean warming rates for the twenty-first century differ substantially among the scenarios after 2035, whereas for precipitation the range is much wider than the precipitation trend.

the cause for the systematic cold and wet bias in the GCMs; however, the typically poor performance of the models in the TP is likely linked to the coarse resolution of the models. The complex topography in the TP can induce many processes such as local circulation (e.g., mesoscale mountain/valley wind) that cannot be fully accounted for by the models due to their course resolution. Giorgi and Marinucci (1996) suggest that the role of topography is dominant in simulated precipitation, especially in Alpine regions characterized by complex topographical features. Kim et al. (2008) show that as the resolution increases, various monsoon regimes affected by mesoscale terrains exhibit improved details in the GCMs simulations of the monsoon demarcation, especially along the steep slope of the Tibetan Plateau.
In this study, the models with least biases for mean annual precipitation, IPSL-CM5A-LR, MRI-CGCM3, IPSL-CM5A-MR, HadCM3, and CanESM2 (Fig. 7), have resolutions that are neither the highest nor lowest of the 24 models, as did the models with the largest bias, indicating that the slight improvement in the spatial resolution does not help reduce the biases in this region.

The mean cold bias in the CMIP5 models is largest in winter and smallest in summer over the TP. This seasonal pattern of cold bias in the GCMs is consistent with previous studies, such as in the Arctic (Chapman and Walsh 2007) and East Asia (Christensen et al. 2007). And the largest cold biases often appear in areas with varying topography and permanent ice (e.g., Mao and Robock 1998). This feature may imply a common deficiency in 
near term(2006-2035)

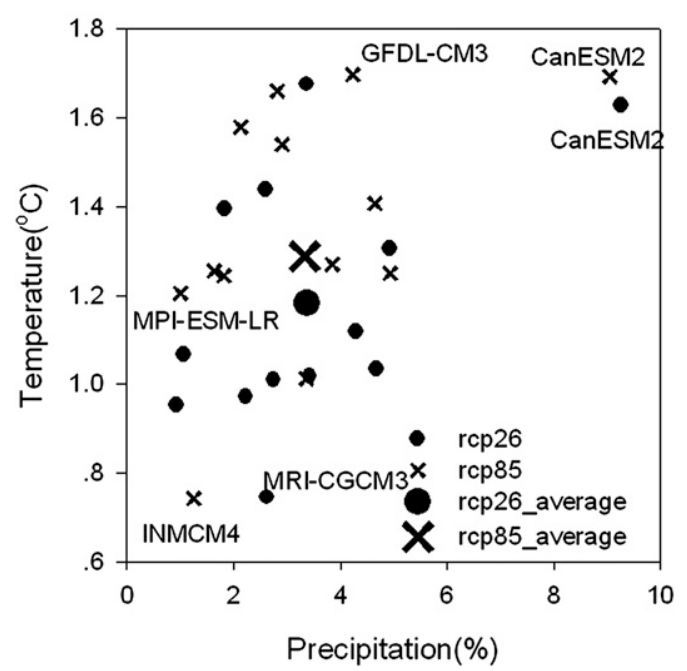

long term(2036-2099)

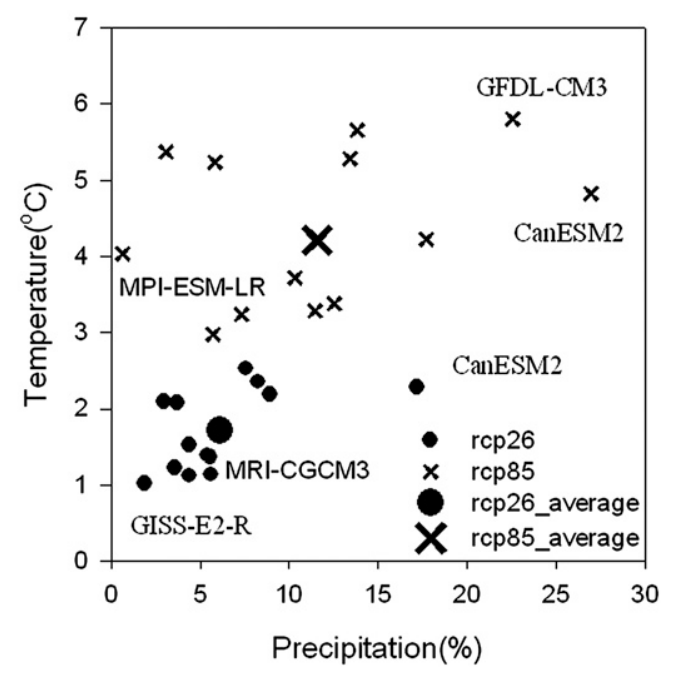

FIG. 13. Scatterplots of change in annually averaged TP temperature and precipitation relative to the 1961-2005 annual mean for each GCM for the near term and long term. Green circles indicate scenario rcp2.6 and blue crosses rcp8.5. The red circle indicates the average mean of rcp2.6, and the red triangle that of rcp8.5.

the representation of snow-ice albedo in the diverse models. It appears that the systematic bias and the significant problems over the mountain regions (e.g., the Tibetan Plateau) still remain in the CMIP5 models. The attribution of the errors requires a detailed diagnostic study with more reliable and independent observations.

The wet bias in the CMIP5 models over the eastern TP may also arise from inadequate spatial representation of the gauge data or the ways in which the gauge data are interpolated to obtain gridded data (Chen et al. 2010). Gauge locations usually tend to lie at low elevations relative to the surrounding terrain. Simple interpolation of point data to grids may not capture the influence of orographic lifting on precipitation, especially in topographically complex regions (Johansson and Chen 2003). Adam et al. (2006) suggest that the correction for orographic effects resulted in a net precipitation increase of $20.2 \%$ in orographically influenced regions. Furthermore, the gauge data used here to evaluate the GCMs do not include any undercatch corrections. Ye et al. (2004) bias-corrected 710 meteorological stations in China for wind-induced undercatch, a trace amount of precipitation, and wetting loss (Ye et al. 2004). Their results suggest that the undercatch correction has increased $19 \%$ of the annual mean precipitation from the 710 stations. Therefore, the gauge precipitation in this work used to evaluate the GCMs on the TP could be increased $40 \%$ if included both undercatch and orographic effects. However, even after adding $40 \%$ more to the gauge observations, most of the GCMs would still overestimate $15 \%-97 \%$ of adjusted observed precipitation. The fact that most GCMs tend to underestimate observed temperature and overestimate observed precipitation over the TP reflects systematic model biases, especially for complex regions such as the TP. The results of this study may draw attention of the modeling groups for further improving the GCMs performance in the complex regions.

It is important to note that different statistical measures used in the evaluation show different aspects of climate and their separate application may lead to different conclusions. Brekke et al. (2008) suggest that use of a greater number of metrics leads to less apparent difference among models (Brekke et al. 2008). In this work, we choose some commonly used metrics to evaluate the performance of GCMs. The top five models (Table 6) change depending on the statistical indicators used. Note that no model falls in the best five for both temperature and precipitation, and likewise no model falls in the worst five for both temperature and precipitation. Consistent with previous studies in other areas (e.g., Mote and Salathé 2010; Reichler and Kim 2008; Phillips and Gleckler 2006), the ensemble mean generally shows closer agreements with observations than does any single model over the TP. Therefore, we have more confidence in the model ensembles in simulating the TP climate.

\section{Conclusions}

The performances of the 24 GCMs in the CMIP5 in simulating recent past climate (1961-2005) over the 

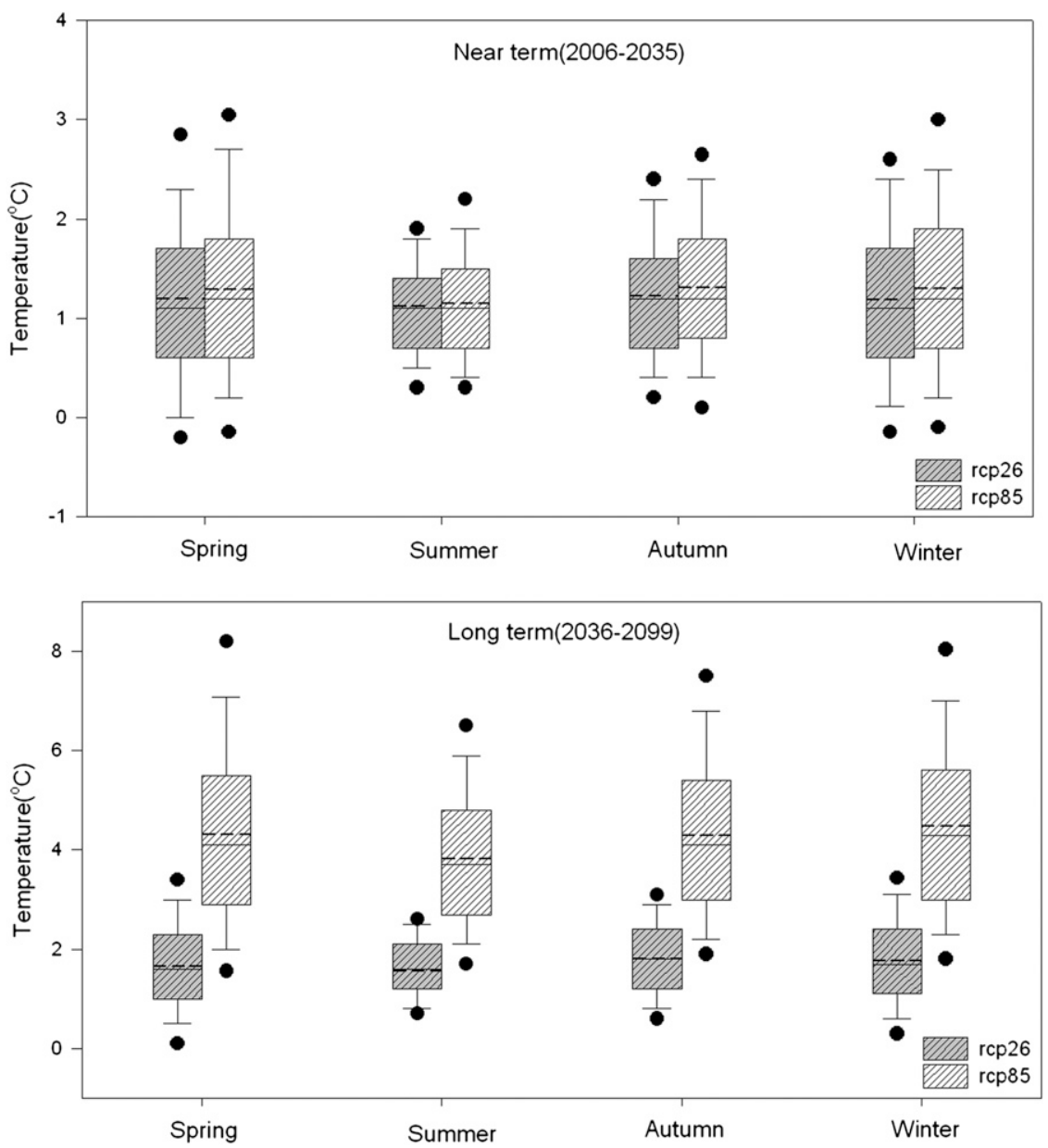

FIG. 14. Range (lowest to highest) of projected changes in temperature for each season, relative to the 1961-2005 mean for that season. In each pair of box-and-whisker plots, the left one is for rcp2.6 and the right for rcp8.5. Black dots are extreme outliers (5th and 95th percentiles). Box-and-whisker plots indicate the 10th and 90th percentiles (whiskers), 25th and 75 th percentiles (box ends), and median (black solid middle bar). The red solid middle bars are the ensemble averages of all GCMs for each season and scenario.

eastern TP were evaluated against observations from 176 meteorological stations. The models' projected changes over the TP in the twenty-first century climate relative to those of the 1961-2005 were also described. The main results are summarized as follows:

1) Most GCMs are able to fairly well capture the climatological annual mean, seasonal, and spatial variations of the observed temperature. However, the models tend to have cold biases in comparison with the observations, with a mean underestimation of $1.1^{\circ}-2.5^{\circ} \mathrm{C}$ for the months December-April and less than $1^{\circ} \mathrm{C}$ for June-October. Winter shows the biggest cold bias, which points to possible deficiencies in snow-ice feedback processes in the models.
2) For precipitation, all the GCMs tend to overestimate the observations in climatological annual means by $62.0 \%-183.0 \%$. Only half of the $24 \mathrm{GCMs}$ are able to reasonably reproduce the observed seasonal pattern including the sharp contrast between dry winters and wet summers. The physics and the temporal and spatial characteristics of precipitation are complex. Improving the ability of models to simulate precipitation should be a priority for climate modelers.

3) For temperature, GFDL-ESM2M, MPI-ESM-LR, GFDL-ESM2G, CanESM2, and CanCM4 rank the top five in terms of systematic error (or bias); for precipitation, IPSL-CM5A-LR, MRI-CGCM3, IPSLCM5A-MR, HadCM3, and CanESM2 perform the best in terms of bias. This means that model performances are variable dependent. 

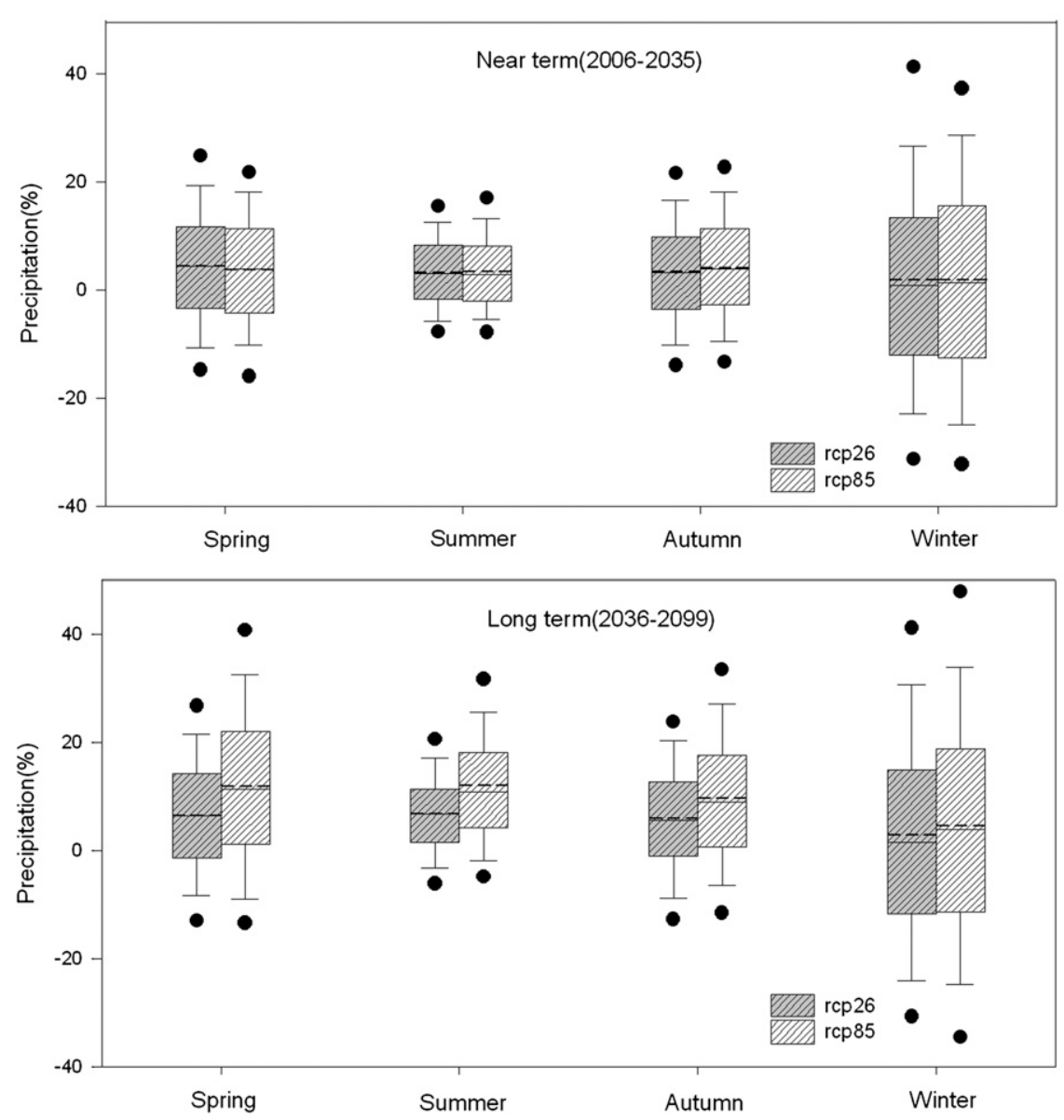

FIG. 15. As in Fig. 14, but for precipitation. Unlike for temperature, for any season some models project increases and some project decreases, although most of the ensemble averages project increases especially in the long term period.

4) All models produce a warming trend in the twentyfirst century under rep8.5; in contrast, rep2.6 predicts a lower average warming rate for the near term, and a small cooling trend in the long-term period with the decreasing radiative forcing.

5) In the near term, the projected temperature changes show weak seasonality and little difference between scenarios, with mean increases of $1.1^{\circ}-1.4^{\circ} \mathrm{C}$ across the seasons. The largest differences between scenarios and the highest warming rates appear in the long term, with the mean warming of $1.7^{\circ}-2.0^{\circ} \mathrm{C}$ among the four seasons under rep2.6, and $3.9^{\circ}-4.6^{\circ} \mathrm{C}$ under rcp8.5.

6) Precipitation is generally projected to increase in the twenty-first century. In the near term, precipitation is projected to increase $5.0 \%-7.0 \%$ in summer, autumn, and spring and $2.0 \%-4.0 \%$ in winter; in the long term, the projected changes and the difference between scenarios increases with time, with $10.0 \%-$ $15.0 \%$ in spring, summer, and autumn and $6.0 \%$ in

TABLE 6. Top five models in terms of different annual statistical indicators.

\begin{tabular}{|c|c|c|c|c|c|c|}
\hline & Rank & 1 & 2 & 3 & 4 & 5 \\
\hline \multirow[t]{3}{*}{ Precipitation } & RE & IPSL-CM5A-LR & MRI-CGCM3 & IPSL-CM5A-MR & HadCM3 & CanESM2 \\
\hline & $R$ & MIROC5 & NorESM1-M & MPI-ESM-LR & MIROC4h & HadGEM2-ES \\
\hline & RMSE & IPSL-CM5A-LR & MRI-CGCM3 & IPSL-CM5A-MR & CanESM2 & CSIRO-MK3 \\
\hline \multirow[t]{3}{*}{ Temperature } & Bias & GFDL-ESM2M & MPI-ESM-LR & GFDL-ESM2G & CanESM2 & CanCM4 \\
\hline & $R$ & BCC-CSM1.1 & HadGEM2-ES & CSIRO-MK3 & ACCESS1.0 & IPSL-CM5A-LR \\
\hline & RMSE & MPI-ESM-LR & GFDL-ESM2M & GFDL-ESM2G & CanCM4 & CanESM2 \\
\hline
\end{tabular}


winter under rcp8.5. The mean increases under rcp2.6 are half of those under rcp8.5 in the long term.

To evaluate the possible impacts of future climate changes on the hydrology and water resources of the TP, a hydrology model could be used by taking the GCM outputs as the inputs. However, given the coarse spatial resolutions and the obvious errors of the GCMs, a downscaling and bias-correction process (Wood et al. 2002) is necessary before taking the GCM outputs for hydrology models. Furthermore, over the next 90 years, projections differ much more among various models than among emissions scenarios for both temperature and precipitation. To account for this uncertainty, using the outputs of multimodel ensembles may be an appropriate approach.

Acknowledgments. This work was supported by the National Basic Research Program of China (973 program) (2010CB951702), the National Natural Science Foundation of China (41190081, 41171051), and the Chinese Academy of Sciences "100-Talents" Program to the Institute of Tibetan Plateau Research, Chinese Academy of Sciences.

\section{REFERENCES}

Adam, J. C., E. A. Clark, D. P. Lettenmaier, and E. F. Wood, 2006: Correction of global precipitation products for orographic effects. J. Climate, 19, 15-38.

Bader, D., C. Covey, W. Gutowski, I. Held, K. Kunkel, R. Miller, R. Tokmakian, and M. Zhang, 2008: Climate models: An assessment of strengths and limitations. U.S. Department of Energy, 123 pp. [Available online at http://www.climatescience. gov/Library/sap/sap3-1/final-report/sap3-1-final-all.pdf.]

Brekke, L. D., M. D. Dettinger, E. P. Maurer, and M. Anderson, 2008: Significance of model credibility in estimating climate projection distributions for regional hydroclimatological risk assessments. Climatic Change, 89, 371-394.

Chapman, W. L., and J. E. Walsh, 2007: Simulations of arctic temperature and pressure by global coupled models. J. Climate, 20, 609-632.

Chen, D., T. Ou, L. Gong, C. Y. Xu, W. Li, C. H. Ho, and W. Qian, 2010: Spatial interpolation of daily precipitation in China: 1951-2005. Adv. Atmos. Sci., 27, 1221-1232.

Christensen, J. H., and Coauthors, 2007: Regional climate projections. Climate Change 2007: The Physical Science Basis, Solomon et al., Eds., Cambridge University Press, 847-940.

Duan, A., and G. Wu, 2005: Role of the Tibetan Plateau thermal forcing in the summer climate patterns over subtropical Asia. Climate Dyn., 24, 793-807.

- — - Q. Zhang, and Y. Liu, 2006: New proofs of the recent climate warming over the Tibetan Plateau as a result of the increasing greenhouse gases emissions. Chin. Sci. Bull., 51, $1396-1400$.

Duan, Q., and T. J. Phillips, 2010: Bayesian estimation of local signal and noise in multimodel simulations of climate change. J. Geophys. Res., 115, D18123, doi:10.1029/2009JD013654.
Giorgi, F., and M. Marinucci, 1996: An investigation of the sensitivity of simulated precipitation to model resolution and its implications for climate studies. Mon. Wea. Rev., 124, 148-166.

Immerzeel, W. W., L. P. H. Van Beek, and M. F. P. Bierkens, 2010: Climate change will affect the Asian water towers. Science, 328, 1382-1385.

Johansson, B., and D. Chen, 2003: The influence of wind and topography on precipitation distribution in Sweden: Statistical analysis and modelling. Int. J. Climatol., 23, 1523-1535.

Kim, H. J., B. Wang, and Q. Ding, 2008: The global monsoon variability simulated by CMIP3 coupled climate models. J. Climate, 21, 5271-5294.

Liu, X., and B. Chen, 2000: Climatic warming in the Tibetan Plateau during recent decades. Int. J. Climatol., 20, 1729-1742.

Mao, J., and A. Robock, 1998: Surface air temperature simulations by AMIP general circulation models: Volcanic and ENSO signals and systematic errors. J. Climate, 11, 1538-1552.

Meehl, G. A., and Coauthors, 2007: Global climate projections. Climate Change 2007: The Physical Science Basis, S. Solomon et al., Eds., Cambridge University Press, 747-845.

Moss, R. H., and Coauthors, 2010: The next generation of scenarios for climate change research and assessment. Nature, 463, 747756.

Mote, P. W., and E. P. Salathé, 2010: Future climate in the Pacific Northwest. Climatic Change, 109, 29-50.

Phillips, T. J., and P. J. Gleckler, 2006: Evaluation of continental precipitation in 20th century climate simulations: The utility of multimodel statistics. Water Resour. Res., 42, W03202, doi:10.1029/2005WR004313.

Qiu, J., 2008: China: The third pole. Nature, 454, 393-396.

Randall, D. A., and Coauthors, 2007: Climate models and their evaluation. Climate Change 2007: The Physical Science Basis, S. Solomon et al., Eds., Cambridge University Press, 589662.

Reichler, T., and J. Kim, 2008: How well do coupled models simulate today's climate? Bull. Amer. Meteor. Soc., 89, 303-311.

Sato, T., and F. Kimura, 2007: How does the Tibetan Plateau affect the transition of Indian monsoon rainfall? Mon. Wea. Rev., 135, 2006-2015.

Solomon, S., D. Qin, M. Manning, M. Marquis, K. Averyt, M. M. B. Tignor, H. L. Miller Jr., and Z. Chen, Eds., 2007: Climate Change 2007: The Physical Science Basis. Cambridge University Press, $996 \mathrm{pp}$.

Thompson, L., T. Yao, E. Mosley-Thompson, M. Davis, K. Henderson, and P. N. Lin, 2000: A high-resolution millennial record of the South Asian monsoon from Himalayan ice cores. Science, 289, 1916-1919.

van Vuuren, D. P., and Coauthors, 2011: The representative concentration pathways: An overview. Climatic Change, 109, $5-31$.

Walsh, J. E., W. L. Chapman, V. Romanovsky, J. H. Christensen, and M. Stendel, 2008: Global climate model performance over Alaska and Greenland. J. Climate, 21, 6156-6174.

Wang, B., Q. Bao, B. Hoskins, G. Wu, and Y. Liu, 2008: Tibetan Plateau warming and precipitation changes in East Asia. Geophys. Res. Lett., 35, L14702, doi:10.1029/2008GL034330.

Wood, A. W., E. P. Maurer, A. Kumar, and D. P. Lettenmaier, 2002: Long-range experimental hydrologic forecasting for the eastern United States. J. Geophys. Res., 107, 4429, doi:10.1029/ 2001JD000659.

Wu, Q., and T. Zhang, 2008: Recent permafrost warming on the Qinghai-Tibetan Plateau. J. Geophys. Res., 113, D13108, doi:10.1029/2007JD009539. 
and 2010: Changes in active layer thickness over the Qinghai-Tibetan Plateau from 1995 to 2007. J. Geophys. Res., 115, D09107, doi:10.1029/2009JD012974.

Yanai, M., C. Li, and Z. Song, 1992: Seasonal heating of the Tibetan Plateau and its effects on the evolution of the Asian summer monsoon. J. Meteor. Soc. Japan, 70, 319-351.

Yao, T., Y. Wang, S. Liu, J. Pu, Y. Shen, and A. Lu, 2004: Recent glacial retreat in High Asia in China and its impact on water resource in northwest China. Sci. China Ser. D: Earth Sci., 47, 1065-1075.

Ye, B., D. Yang, Y. Ding, T. Han, and T. Koike, 2004: A biascorrected precipitation climatology for China. J. Hydrometeor., 5, 1147-1160.

Zhang, Q., and S. Wu, Eds., 2000: Mountain Geoecology and Sustainable Development of the Tibetan Plateau. GeoJournal Library Series, Vol. 57, Springer, 394 pp. 